NBER WORKING PAPER SERIES

\title{
SOLVING SHORTAGE IN A PRICELESS MARKET: INSIGHTS FROM BLOOD DONATION
}

\author{
Tianshu Sun \\ Susan Feng Lu \\ Ginger Zhe Jin \\ Working Paper 21312 \\ http://www.nber.org/papers/w21312
NATIONAL BUREAU OF ECONOMIC RESEARCH
1050 Massachusetts Avenue
Cambridge, MA 02138 \\ July 2015
}

We thank Rena Conti, Jessica Goldberg, Tamara Konetzka, Soohyung Lee, Andrew Sfekas, Fabrice Smieliauskas, Lesley Turner, and participants at International Industrial Organization Conference 2015 as well as at seminars at University of Maryland and University of Chicago for constructive comments. Sun acknowledges the support of Doctoral Research Grant from CIBER at University of Maryland. We also thank the staff at the blood bank that provided the data for tirelessly explaining the institution and answering our questions. This paper would not exist without their help. All errors are ours. All rights reserved. The views expressed herein are those of the authors and do not necessarily reflect the views of the National Bureau of Economic Research.

NBER working papers are circulated for discussion and comment purposes. They have not been peerreviewed or been subject to the review by the NBER Board of Directors that accompanies official NBER publications.

(C) 2015 by Tianshu Sun, Susan Feng Lu, and Ginger Zhe Jin. All rights reserved. Short sections of text, not to exceed two paragraphs, may be quoted without explicit permission provided that full credit, including $\odot$ notice, is given to the source. 
Solving Shortage in a Priceless Market: Insights from Blood Donation

Tianshu Sun, Susan Feng Lu, and Ginger Zhe Jin

NBER Working Paper No. 21312

July 2015

JEL No. D47,D83,I18

\begin{abstract}
Shortage is common in many markets, such as those for human organs or blood, but the problem is often difficult to solve through price adjustment, given safety and ethical concerns. In this paper, we investigate whether market designers can use non-price methods to address shortage. Specifically, we study two methods that are used to alleviate shortage in the market for human blood. The first method is informing existing donors of a current shortage via a mobile message and encouraging them to donate voluntarily. The second method is asking the patient's family or friends to donate in a family replacement (FR) program at the time of shortage. We are interested in both the short-run and long-run effects of these methods on blood supply. Using 447,357 individual donation records across 8 years from a large Chinese blood bank, we show that both methods are effective in addressing blood shortage in the short run but have different implications for total blood supply in the long run. Specifically, we find that a shortage message leads to significantly more donations among existing donors within the first six months but has no effect afterwards. In comparison, a family replacement program has a small positive effect in encouraging existing donors (who donated before the FR) to donate more blood voluntarily after their FR donation, but discourages no-history donors (whose first donation is the FR) from donating in the long run. We compare the effect and efficiency of these methods and discuss their applications under different scenarios to alleviate shortage.
\end{abstract}

Tianshu Sun

Robert H. Smith School of Business

3330 Van Munching Hall

College Park, MD 20742

tianshusun@rhsmith.umd.edu

Susan Feng Lu

KRA 441

Krannert School of Management

Purdue University

Rochester, NY, 14620

lu428@purdue.edu
Ginger Zhe Jin

University of Maryland

Department of Economics

3115F Tydings Hall

College Park, MD 20742-7211

and NBER

jin@econ.umd.edu 


\section{Introduction}

When market supply falls short of market demand, economists often recommend price adjustment to clear the market. However, due to safety and ethical concerns, many markets prohibit price adjustments or do not allow a market price to exist at all (Roth 2007). Organ, tissue, and blood donations are prominent examples. A stream of research has examined how matching mechanisms can increase the number of kidney transplants conditional on a pool of people who have already expressed an intent to donate (Roth et al. 2004, 2005). However, the number of donors is still low relative to the increasing demand, which highlights the importance of recruiting new donors (Kessler and Roth 2012, 2014). Economic incentive (Lacetera et al. 2012, 2013) and alternative allocation policies (Kessler and Roth 2012) have been proposed to increase donations. While effective, much uncertainty and many restrictions still remain in implementing these proposals (WHO 2009, Lacetera et al. 2013). Thus, recent research has called for studies on alternative methods to induce donations (Lacetera et al. 2014, Goette et al. 2010).

To answer this call, we study the impact of non-price methods in addressing shortage. Specifically, we are interested in three questions. First, can market designers utilize "shortage" as a tool to increase the "warm glow" donors get from donation and therefore stimulate market supply? ${ }^{1}$. Second, even if shortage-based methods lead to greater supply in the short run, will the effect last in the long run? Third, in the short and long run, can shortage-based methods help recruit and retain new donors? To address these questions, we study two shortage-based non-price methods that practitioners often consider in a classic priceless market - blood donation - but our findings may be generalized to other priceless markets with shortage, such as those for human organs or tissue (Kessler and Roth 2014).

Shortage is common and frequent in the human blood market (Slonim et al. 2014). Figure 1 presents a World Health Organization (WHO) map of donation rate as of 2007. Countries that have low donation rate per capita are often poor and suffer from long-lasting blood shortage. In contrast, mid-to-high income countries have relatively high donation rates and are more likely to experience seasonal or type-specific shortage due to unexpected attritions or emergency events. Mostly driven by quality concerns, the WHO advocates for $100 \%$ unpaid voluntary donation for

\footnotetext{
${ }^{1}$ Given the difficulty of distinguishing pure altruism from the warm feeling of doing good for others, we refer to both as the "warm glow". In the economics literature, altruistic individuals are assumed to gain utility from increasing the welfare of others, while individuals motivated by the warm feeling of doing good receive utility from their own contributions directly (Andreoni, 1989; 1990). Studies in the lab and the field have confirmed the importance of warm feelings (Crumper and Grossman 2008, DellaVigna et al. 2012), and find that donations connected with a greater sense of need or deservingness also create more warm feelings (Konow 2010). In our context, it is difficult to distinguish altruism from warm feelings, so we refer to both as the warm glow.
} 
all medical use of human blood. ${ }^{2}$ But this goal is hard to reach in many countries. As of 2012, 73 countries collected over $90 \%$ of their blood supply from voluntary unpaid blood donors; however, 72 countries collected more than $50 \%$ of their blood supply from family replacement or paid donors (WHO 2014).

Facing shortage and a ban on monetary incentive, blood banks often resort to two methods to meet their needs. First, they strive to recruit more unpaid voluntary donors by conveying shortage information to past donors in order to induce a warm glow and increase donation. However, if shortage is too severe or too frequent, donor recruitment via the shortage message alone may not be sufficient to close the gap. Another method is implementing a family replacement (FR) program. At the time of shortage, a patient in need of blood can be given the option to recruit their family or friends to donate blood so that the patient can use the blood immediately. In practice, because not all blood types can be transfused safely between individuals, the blood bank swaps FR donation with the same amount of blood from the inventory for the dedicated patient.

These two methods have different pros and cons. First, the blood bank can choose exactly to whom and when to send the shortage message, but the FR depends on the random arrival rate of patients and the patients' ability to recruit potential donors. Second, if the FR program is able to generate additional donations in the short run, they are proportional to the level of shortage. In contrast, the donation amount from the shortage message is more uncertain. Third, the shortage message targets existing donors only, but the FR program can motivate donations from individuals who have never donated before or would never donate voluntarily in the future. By specifying the immediate recipient of the donation (a friend/family member in need of blood), FR treatment can generate even more of a warm glow from FR donors (Fong and Luttmer 2009, List and Price 2009). Such a warm glow may last in the long run and expand beyond one's close social network. Finally, FR shifts the burden of donor recruitment from the blood bank to individual patients, which could cut the cost of recruitment by 75 to 87 percent. ${ }^{3}$

Neither the shortage message nor FR donation is immune from the risk of reducing the blood supply in the long run. Specifically, this downside risk may arise through two mechanisms. First, theoretically and empirically, economists have shown that some individuals are conditional

\footnotetext{
${ }^{2}$ WHO (2009) stated that "more than 30 years after the first World Health Assembly resolution (WHA28.72) .... family replacement and paid donation continue in many countries even though there is convincing evidence that they are both less safe and that their use can inhibit progress to a safer system based on 100\% VNRBD." VNRBD stands for $100 \%$ voluntary non-remunerated blood donation.

${ }^{3}$ As shown in Bates et al. (2007), the cost of getting blood from voluntary donors recruited and screened at transfusion centers is four to eight times as much as the cost of obtaining blood from hospital-based FR donation. It is usually the bank's responsibility to find voluntary donors, whereas the burden of finding FR donors falls on the patient's family.
} 
cooperators who are more willing to contribute to a public good when they learn that others do so as well. ${ }^{4}$ In our context, both the shortage message and FR donation convey credible information about others' (insufficient) donation and therefore could reduce the incentive to donate among those who value conditional cooperation. We refer to this effect as "distrust." Moreover, the FR program allows blood donations to be shared with family/friends rather than with the general public. While this could reduce one's incentive to free ride, it may also create an incentive to save the blood for one's small social circle and crowd out the incentive to donate for the society. We refer to this substitution effect between the intrinsic motivation for the public and the private incentive for one's own friends and family as a "crowd-out."

Second, the FR program also raises a concern about blood quality. The implementation of the FR program could encourage desperate patients to hire professional donors as "friends" and thus jeopardize blood quality. For this reason, the WHO recommends phasing out FR donation and eliminating paid donation. Nevertheless, researchers have found mixed evidence regarding the blood quality of FR donors: on one hand, Abdel Messih et al. (2014) use Egyptian data to show that the prevalence of transfusion-transmissible infections is much higher among FR donors than among voluntary donors; on the other hand, Allain et al. (2010) compare FR donors with first-time voluntary donors in West Africa and find their blood quality to be similar.

From a policy maker's point of view, it is essential to understand the tradeoff between these downside risks and the positive benefits arising from the shortage message and the FR program in both the short run and long run, before deciding when to pursue which method to alleviate shortage. To answer this question, we employ a unique large dataset consisting of 447,357 individual donation records across 8 years.

Our data come from a large blood bank located in a major city in southeast China with a population of over 8 million as of 2012. Since 2010, the city has faced an increasingly severe blood shortage, partly due to increased demand. The bank has used both the mobile message and the FR program to address the blood shortage.

For both methods, it is not easy to quantify the tradeoffs facing the blood bank because individual motives are often unobservable. Fortunately, our data contain over 330,000 individual donors and their donation history from 2005 to 2013, which allows us to find control individuals that are closely matched with individuals who either received the shortage message or donated via FR. As detailed below, the effect of the shortage message is cleanly identified because sometimes

\footnotetext{
${ }^{4}$ See Andreoni (1988) and Fischbacher et al. (2001) for theoretical models on conditional cooperation and reciprocity. See Fischbacher et al. (2001), Potters, Sefton and Vesterlund (2005), Frey and Meier (2004) for lab evidence, and Shang and Croson (2008, 2009), Martin and Randal (2008), Allcott (2011), and Shang and Cronson (2008) for evidence from field experiments.
} 
the blood supply is short for only certain blood type(s), which gives us exogeneity in terms of who received a shortage message specific to the blood type in short supply. The variation in FR and non-FR donation is less clean, because individuals may self-select into FR donation through unobserved process. We articulate the implication of such selection and find a way to separate the causal effect of the FR program from potential selection.

Comparing treated and control individuals, we find that a shortage message leads to more donations among existing donors within the first six months but no significant effect afterwards. This effect is stronger for donors who donated more times before receiving the shortage message, suggesting a greater warm glow effect for donors who are more pro-social. In comparison, FR donation has a small long-run positive effect in encouraging existing donors (who donated before the FR) to donate more blood voluntarily after their FR donation, but discourages no-history donors (whose first donation is FR) from donating in the long run. This is consistent with findings on the effect of shortage message and suggests that the warm glow dominates the crowd-out and distrust effects for donors who are more pro-social ${ }^{5}$, while crowd-out and distrust effects are more prevalent for donors who are less pro-social. In addition, we do not find evidence that FR programs lead to worse blood quality. Overall, the increase in blood supply from both shortage messages and FR is large and comparable to the effect of high-stake economic incentives reported in recent literature (Lactera et al. 2014, Iajya et al. 2013, Goette and Stutzer 2008).

Because neither treatment worsens blood quality, the efficiency comparison between the two methods is largely dependent on level of control, targeted audience, cost of implementation, and the effects of treatment in the short and long runs. Back-of-envelope calculation suggests that the shortage message can be used in places where the donor population is large and the shortage is less severe and type-specific, while FR could be more useful in generating a significant blood supply in the short run when the donor population is small and the shortage is severe and general. However, in the long run, the distrust or crowd-out effects of FR may exacerbate the shortage problem, especially in a society with a low donation rate (which may be the reason for a severe shortage to begin with).

Our findings contribute to the existing literature in three ways. First, previous studies have examined the effect of altruism, social image, social pressure, empathy and other non-price methods on donation (Andreoni and Rao 2011, DellaVigna et al. 2012, Edwards and List 2014, Lacetera and Macis 2010, Stutzer and Goette 2012), but those methods did not target shortage specifically. We extend this literature stream and examine whether (and, if so, how) informing

\footnotetext{
${ }^{5}$ By pro-social, we mean that either the donor is more altruistic or she derives more private benefits from donation in terms of warm glow, social image, etc.
} 
donors about shortage can help to induce more donations and alleviate shortage. Compared with mobile messages sent by the same bank that do not mention a "shortage" (as documented by Sun et al. 2015 in a field experiment), the "shortage-based" message studied in this paper is five times more effective in terms of response rate. In addition, we are among the first social scientists to study the FR program, which is based on shortage by definition. ${ }^{6}$ Second, while most studies have focused on driving donations from existing donors (Lacetera et al. 2014), our study shows that an FR program can be effective in reaching and recruiting new donors at a relatively low cost. Since most such donors may otherwise never donate, their contribution represents a net increase in the blood supply. Third, most studies of blood donation have focused on the short-run effect. The only exceptions we are aware of are Lacetera et al. (2012, 2014), who found no significant longrun effect of economic incentives. Our study, which uses a unique panel dataset across 8 years, is among the first to identify a significant long-run impact of non-price interventions in blood donation ${ }^{7}$. More interestingly, we find that the long-run effect differs across the two shortagebased methods and varies from existing to new donors. The contrast between short-run and longrun effects is important for market designers to evaluate non-price interventions.

\section{Potential Effects and Econometric Identification}

While the shortage message and the FR program are two commonly used methods to alleviate blood shortage, they may vary by targeted audience. In principle, both the shortage message and the FR program can be applied to existing donors and those that have never donated before the invention time (referred to as no-history donors). In practice, blood banks, including the one in our study, often target messages toward existing donors (see the discussion of such practice in previous studies, Lacetera et al. 2014), and implement FR programs quietly for both existing and no-history donors conditional on their families or friends needing blood in a hospital and there being a blood shortage at the time.

\subsection{Effects of shortage message}

For existing donors, the shortage message can have a mixed effect on willingness to donate. On the positive side, shortage implies that the donated blood can be used immediately on someone that needs blood, which increases the donor's perceived benefits from unpaid voluntary

\footnotetext{
${ }^{6}$ Iajya et al. (2013) assessed the impact of information, social prestige and financial rewards on voluntary blood donations in Argentina, where $88 \%$ of blood donations are emergency/replacement donations. However, their study does not examine the effect of replacement donation on future voluntary donation.

${ }^{7}$ Some interventions are found to have long run impact in other contexts. For example, Charness and Gneezy (2009) found that temporary incentives can affect longer term behavior in physical exercise.
} 
donation. The perceived benefits - which we refer to as the warm glow - may come from pure altruism or a warm feeling of doing good for people in need, both of which may be more salient in the case of a type-specific shortage. Note that the extra 'warm glow' from donating in response to a shortage message is tied to that specific shortage and therefore is likely to be a short-run effect. The warm glow effect of the shortage message may also differ by donor type, which could be characterized by the number of voluntary donations a donor made before the intervention time (N). Let us call donors with $\mathrm{N}>1$ frequent donors and donors with $\mathrm{N}=1$ infrequent donors. If frequent donors donate more frequently because they derive more of a warm glow from voluntary donation, the shortage message may generate more of a warm glow for them than for infrequent donors.

On the negative side, shortage may change an existing donor's belief regarding how the rest of the community contributes to the public good. If the donor believes that shortage occurs because the rest of the community contributes too little, she may become less motivated for future donation (Frey and Meier 2004). This negative effect on conditional cooperation - referred to as distrust - can occur in both the short and long runs. There could also be a crowd-out effect: if a donor has planned to donate 10 months later but decides to donate early in response to the shortage message, the message may simply substitute a future donation for a current donation.

Above all, if the data offer an exogenous variation in shortage message, and we can find control donor(s) for every treated donor that receives this exogenous message, the sign of the aggregate effect should be informative as to the competition between the above mentioned effects. In particular, the effect will be positive in the short run and zero afterwards if the warm glow dominates over distrust and there is no crowd-out. If distrust is the main effect, the aggregate effect should be negative in both the short and long runs. If crowd-out exists (in combination with the warm glow in the short run), we expect the aggregate effect to be positive in the short run and negative in the long run.

The econometric model is straightforward. We first match a treated individual $i$ with individual(s) that have the same demographics and donation history as $i$ but do not receive the message, calling the pair group $g$. As detailed below, because the studied shortage messages are specific to certain blood types (A and B), we limit control individuals to other blood types $(\mathrm{O}$ and $\mathrm{AB})$. To the extent that type-specific shortage is exogenous and people of different blood types are comparable conditional on the same demographics and donation history, we have a clean comparison within each treated-control pair. We then run a typical difference-in-differences regression, where $y_{i t}$ denotes whether $i$ donates voluntarily at time $t, 1_{m s g, i}$ is a dummy for the 
treated individuals, and $1_{a f t, t}$ is a set of dummies equal to one if $t$ is in a specific half year at or after the time of the message:

$$
y_{i t}=\alpha_{i}+\alpha_{t}+\beta_{m s g} \cdot \sum_{t=T}^{T \in\{0,>0\}} 1_{m s g, i} \cdot 1_{a f t, t}+\varepsilon_{i t} .
$$

One caveat of the above identification strategy is that we compare the effect of receiving a shortage message and the effect of receiving no message. Strictly speaking, receiving a shortage message entails two treatments: one is receiving a message that simply asks for voluntary donation, and we refer to this as an "ask" treatment; the other is acquiring information about ongoing blood shortage (specific to a blood type), and we refer to this as a "shortage" treatment. The identified coefficient of $\beta_{m s g}$ captures both treatments. If the bank's goal is to compare the mobile message and the FR program, it does not need to distinguish between the two treatment effects of the shortage message. However, for research purposes, distinguishing the two treatment effects will highlight the extra effect of emphasizing "shortage" on top of the simple effect of "ask."

As documented in Sun et al. (2015), the same blood bank conducted a randomized field experiment in 2014, in which the baseline treatment was sending a mobile message that asked for voluntary donation without any mention of a shortage. Compared to the control group of no message at all, this treatment generated a positive $0.27 \%$ effect on the probability of donation. To the extent that this treatment effect captures the pure effect of "ask" and is comparable to the "ask effect" of the shortage message studied here, the effect of the "shortage" treatment was $\beta_{m s}{ }^{-}$ $0.27 \%$.

\subsection{Effects of FR}

FR is more complicated than a shortage message. In addition to conveying shortage, a record of FR donation implies another two pieces of information. First, the donor knows that her FR donation benefits a family or friend rather than an unknown stranger. As suggested in previous literature, individuals are typically more altruistic towards family and friends or derive greater warm feelings from social ties (Fong and Luttmer 2009, List and Price 2009, Leider et.al. 2009). By donating to one's own friend or family member, the FR donor has an opportunity to closely observe the benefit of donation for the blood recipient both before and after transfusion. Hence, the warm glow effect of FR can be greater and more long lasting than that of a shortage message alone. However, the same reason could generate a crowd-out effect in the future. If one knows that she can dedicate her blood to family and friends when they need it, she may have an 
incentive to save the blood for her own social circle in the future instead of donating it to the general public. In this sense, the FR program may introduce the danger of reducing the pool of risk sharing and undermining the efficiency of risk pooling.

The second piece of information conveyed by an FR donation record is selection. In principle, the treatment we are interested in is being asked to make an FR donation for a specific patient $^{8}$. However, because FR donation will not occur unless the FR donor has agreed to donate upon request, FR donation is subject to unobserved selection. The magnitude of selection is crucial for the overall evaluation of an FR program. At one extreme, if FR donors are so prosocial that they would have donated voluntarily to the blood bank even if they had not received the FR request, the FR program does not increase the blood supply at all. At the other extreme, if all FR donors are those that will not donate to the blood bank but will donate for their own family and friends, these FR donations will sustain the demand from their family and friends and free up same amount of blood for the rest of the community.

The econometric challenge is how to distinguish the selection effect from the warm glow, distrust, and crowd-out effects.

For an FR donor that has donated via FR at time $\mathrm{t}$ (denoted as $F R_{t}=1$ ), let us assume she carried demographics $\mathrm{X}_{\mathrm{i}}$ and a donation history $\left(\mathrm{H}_{\mathrm{i}}\right)$ before t. There are $\mathrm{M}_{\mathrm{i}}$ number of FR donors that have exactly the same $\left\{X_{i}, H_{i}, F R_{t}\right\}$. In our donation records, we find $\mathrm{N}_{\mathrm{i}}$ individuals that had the same $X_{i}$ and $H_{i}$ before $t$ but did not donate FR. Among these $\mathrm{M}_{\mathrm{i}}+\mathrm{N}_{\mathrm{i}}$ individuals, had the FR not existed, a fraction $\left(\lambda_{\mathrm{i}}\right)$ would have donated voluntarily at $\mathrm{t}$, while the rest $\left(1-\lambda_{\mathrm{i}}\right)$ would not have donated at $t$. The first type (referred to as $V$ type) might be more pro-social than the second (referred to as $\mathrm{N}$ type). These two types of donors, if unaware of FR, will donate in the future with probabilities $p_{V}$ and $p_{N}$ respectively. For simplicity, let $\Delta p$ denote $p_{V}-p_{N}$ :

$$
\begin{gathered}
y_{V}=p_{V}=\Delta p+p_{N} \\
y_{N}=p_{N}
\end{gathered}
$$

Suppose the risk of having a family or friend in need of blood $(\pi)$ is the same for everyone, but the likelihood of agreeing to donate FR is $\theta_{\mathrm{V}}$ for $\mathrm{V}$ type and $\theta_{\mathrm{N}}$ for $\mathrm{N}$ type. Thus, by selection, the ratio of FR donors that have the same $\left\{X_{i}, H_{i}\right\}$ by $\mathrm{t}$ is

$$
\frac{M_{i}}{M_{i}+N_{i}}=\pi \cdot \theta_{V} \cdot \lambda_{i}+\pi \cdot \theta_{N} \cdot\left(1-\lambda_{i}\right)
$$

Conditional on being an FR donor, the probability of donating in the future is the sum of the selection effect and a combination of warm glow, distrust and crowd-out effects $(\omega)$ :

\footnotetext{
${ }^{8}$ Because the blood bank runs the FR program quietly, we assume that potential donors are not aware of the program until being asked to donate under the program.
} 


$$
\begin{gathered}
y_{F R}=\frac{\theta_{V} \cdot \lambda_{i} \cdot p_{V}+\theta_{N} \cdot\left(1-\lambda_{i}\right) \cdot p_{N}}{\theta_{V} \cdot \lambda_{i}+\theta_{N} \cdot\left(1-\lambda_{i}\right)}+\omega \\
=p_{N}+\omega+\Delta p \cdot\left\{\frac{\theta_{V}}{\theta_{N}} \cdot \frac{\lambda_{i}}{1-\lambda_{i}}-\left(\frac{\theta_{V}}{\theta_{N}}\right)^{2} \cdot\left(\frac{\lambda_{i}}{1-\lambda_{i}}\right)^{2}+\left(\frac{\theta_{V}}{\theta_{N}}\right)^{3} \cdot\left(\frac{\lambda_{i}}{1-\lambda_{i}}\right)^{3}-\cdots\right\} \\
\approx p_{N}+\omega+\Delta p \cdot\left\{\frac{\theta_{V}}{\theta_{N}} \cdot \frac{\lambda_{i}}{1-\lambda_{i}}\right\} .
\end{gathered}
$$

Denoting $\Delta \theta=\frac{\theta_{V}}{\theta_{N}}$, add an i.i.d error term and rewriting the above in vectors, we have:

$$
y=\left(\begin{array}{c}
y_{V} \\
y_{N} \\
y_{F R}
\end{array}\right) \approx p_{N} \cdot\left(\begin{array}{l}
1 \\
1 \\
1
\end{array}\right)+\Delta p \cdot\left(\begin{array}{l}
1 \\
0 \\
0
\end{array}\right)+\omega \cdot\left(\begin{array}{l}
0 \\
0 \\
1
\end{array}\right)+\Delta p \cdot \Delta \theta \cdot\left(\begin{array}{c}
0 \\
0 \\
\lambda_{i} \\
\hline 1-\lambda_{i}
\end{array}\right)+\left(\begin{array}{c}
\varepsilon_{V} \\
\varepsilon_{N} \\
\varepsilon_{F R}
\end{array}\right) .
$$

In this equation, the $\omega$ term is the warm glow/distrust/crowd-out effect that applies to each FR donor equally. The last non-error term is the selection effect, which is identifiable from the warm glow/distrust/crowd-out effect of FR because the selection effect depends on $\lambda_{i}$, the proportion of type $\mathrm{V}$ in the $\left\{X_{i}, H_{i}\right\}$ population. If we can have a good proxy for $\frac{\lambda_{i}}{1-\lambda_{i}}$, this equation can be run in linear specifications. One rough proxy for $\frac{\lambda_{i}}{1-\lambda_{i}}$ is the ratio of type $V$ to type $N$ in non-FR donors, which in theory follows:

$$
\frac{N_{V, F R=0}}{N_{N, F R=0}}=\frac{\lambda_{i} \cdot\left(1-\pi \cdot \theta_{V}\right)}{\left(1-\lambda_{i}\right) \cdot\left(1-\pi \cdot \theta_{N}\right)} .
$$

It is not perfect because the non-FR population is already a result of selection, although the selection is arguably small if $\pi$ is very small. Another possibility is computing this ratio before FR is introduced. Empirically, we can calculate the hazard ratio of donating voluntarily at a certain time condition on $\left\{X_{i}, H_{i}\right\}$; this ratio will be a proxy of $\lambda_{i}$ from which we can easily calculate $\frac{\lambda_{i}}{1-\lambda_{i}}$. Once we identify $\Delta p, \Delta \theta$, and $\frac{\lambda_{i}}{1-\lambda_{i}}$, the total selection effect of FR (relative to type N) can be computed as:

$$
\text { selection effect }=\Delta p \cdot\left(1-\frac{1}{1+\Delta \theta \cdot \frac{\lambda_{i}}{1-\lambda_{i}}}\right) .
$$

In the case of no FR, the average voluntary donation per capita will be:

$$
\begin{gathered}
\text { Supply }_{\text {noFR,t }}=\lambda_{i} \cdot 1+\left(1-\lambda_{i}\right) \cdot 0=\lambda_{i} \\
\text { Supply }_{\text {noFR,after } t}=\lambda_{i} \cdot p_{V}+\left(1-\lambda_{i}\right) \cdot p_{N} .
\end{gathered}
$$


By definition, type $\mathrm{V}$ will donate voluntarily at $\mathrm{t}$ for sure and type $\mathrm{N}$ will not donate voluntarily at t. This explains why Supply $y_{n o F, t}$ is just the proportion of type $\mathrm{V}$, which is $\lambda_{i}$.

If FR is introduced for all donors with $\left\{X_{i}, H_{i}\right\}$ at t conditional on their family or friends being in need of blood (the probability of this event is $\pi$ ), the average supply per capita at $t$ and after $\mathrm{t}$ will be:

$$
\begin{aligned}
& \text { Supply }_{F R, t}=(1-\pi) \cdot \text { Supply }_{n o F R, t}+\pi \cdot \theta_{V} \cdot \lambda_{i}+\pi \cdot \theta_{N} \cdot\left(1-\lambda_{i}\right) ; \\
& \text { Supply }_{F R, \text { after } t}=(1-\pi) \cdot \text { Supply }_{\text {noFR,after } t} \\
& +\pi \cdot\left(1-\theta_{V}\right) \cdot \lambda_{i} \cdot p_{V}+\pi \cdot\left(1-\theta_{N}\right) \cdot\left(1-\lambda_{i}\right) \cdot p_{N} \\
& +\pi \cdot\left[\theta_{V} \cdot \lambda_{i}+\theta_{N} \cdot\left(1-\lambda_{i}\right)\right] \cdot y_{F R}
\end{aligned}
$$

Because type $\mathrm{V}$ will denote voluntarily without FR anyway, we will assume type $\mathrm{V}$ will always donate upon an FR request, i.e. $\theta_{V}=1$. Under this assumption, the extra supply due to FR can be written as:

$$
\begin{gathered}
\Delta \text { Supply }_{t}=\pi \cdot\left[\left(\theta_{V}-1\right) \lambda_{i}+\theta_{N}\left(1-\lambda_{i}\right)\right]=\pi \cdot \theta_{N} \cdot\left(1-\lambda_{i}\right) ; \\
\Delta \text { Supply }_{\text {after } t}=\pi \cdot \omega \cdot\left(\lambda_{i}+\theta_{N} \cdot\left(1-\lambda_{i}\right)\right) .
\end{gathered}
$$

In words, the ability of FR to increase blood supply at $t$ depends on the extent to which FR can hit on type $\mathrm{N}$ donors and the rate of converting this hit into donations. After the FR donation, the extra supply due to FR is solely dependent on the warm glow/distrust/crowd-out effect $(\omega)$ because selection alone changes no behavior. This effect applies to all FR donors, including the type $\mathrm{V}$ donors that would have donated voluntarily had there been no FR.

In sum, if we compare just the future donation behavior of an FR donor and the donation behavior of seemingly identical donors that do not donate FR at $t$, the empirical effect will capture both the true warm glow/distrust/crowd-out effect $(\omega)$ and a selection effect. It is important to distinguish the two, as only the former term $(\omega)$ reflects the causal effect of FR on blood supply at time t, while the latter reveals the portion of blood supply from no-history donors, most of whom would not donate otherwise.

The sign of the warm glow/distrust/crowd-out effect $(\omega)$ can tell us whether the positive warm glow effect dominates the negative distrust and crowd-out effect. It is helpful to know whether $\omega$ persists in the long run, as it may indicate whether such a non-price method can increase blood supply in a sustainable way in the long run. Equally important, we are interested in the magnitude of the selection effect, as it may suggest how many new donors the FR program can reach. Most of these new donors would not donate voluntarily and thus are essentially free riders. 
In summary, we present econometric models to estimate the causal effect of a shortage message and an FR program. Two items are worth highlighting: first, receiving the shortage message is not bundled with whether or not one responds to the message, which makes the econometrics clean and simple. But FR donation bundles the receipt of an FR request and a positive response to that request, which is why we need to consider selection in FR donation. Second, the shortage message was sent to existing donors, while FR could hit both existing and no-history donors. Consequently, the effectiveness of FR depends not only on the effect of FR on future donation behavior, but also on the extent to which the FR hits no-history donors at the time of the FR request. This is because no-history donors are by definition more likely to be free riders on the society, and FR serves as a way to motivate these free riders to contribute. We will come back to the magnitude of this effect after we present our data and coefficient estimates.

\section{Data}

\subsection{Data Description}

Our data come from a centralized Chinese blood bank in a provincial capital city with a population of more than 8 million. The blood center is responsible for supplying blood to 18 hospitals in the city and is encouraged to equalize demand and supply of whole blood on its own. ${ }^{9}$

The data cover two forms of whole blood donation: (1) voluntary donation collected by 17 permanent street mobiles spread across the city and by group drives at specific universities, companies and government agencies; (2) directed FR donation for family and friends. The blood center's administrative database includes every donation record from 2005/1/1 to 2013/8/10, tracking the exact time, location, form (voluntary or FR), amount $(200 \mathrm{ml}, 300 \mathrm{ml}$, or $400 \mathrm{ml})$ and quality ("pass" or "fail") of donation, as well as the donor's age, gender, education and marriage status at the time of donation. The blood center carefully removes all identity-related information and identifies each donor by a unique, scrambled donor ID, allowing us to follow the donation behavior of each donor over time.

After deleting individuals who have donated only platelets ${ }^{10}$, the resulting dataset consists of 447,357 episodes of whole blood donation by 335,913 unique donors. Taking donor age as of 2013, Table 1 shows that $31.67 \%$ of the donors are between 18 and 21, 32.47\% between 22 and $25,15.88 \%$ between 26 and 30, 13.42\% between 31 and 40, and the rest $6.56 \%$ are above 40 . The

\footnotetext{
${ }^{9}$ In the rare cases of emergency blood shortage, the blood center may request an extra supply from nearby blood banks, but at extremely high transportation and administration costs. Such a situation is very rare, according to the blood bank staff that we interviewed.

${ }^{10}$ The blood bank handles both platelet and whole blood donations. These two types of donations differ greatly in procedures, locations, and donor population. Platelet donation usually takes place at the centralized location of the blood bank, rather than a street mobile.
} 
majority of the donors (60.85\%) are male. As for other demographics, $80.22 \%$ do not have college degree, $68.33 \%$ are single, $19.35 \%$ have a residential permit (hukou) from the city, $37.54 \%$ have hukou from elsewhere in the same province, $29.69 \%$ have hukou from other provinces, and the remaining $13.41 \%$ have unknown hukou status. The dispersed distribution of hukou status is driven by the fact that this is a capital city of a province with a dense population, and one is allowed to study, work, and carry out military duty in the city even if his/her hukou is from elsewhere.

Table 2 summarizes the data by donation episodes instead of donor identity. Of the total 447,357 donation episodes, $57.48 \%$ are voluntary donations at street mobiles, $38.38 \%$ are voluntary donations at group drives, and the remaining $4.14 \%$ are FR donations. Figure 2 shows the variation over time between voluntary and FR donations. Perceived as the last resort, FR donation was not used until the second quarter of 2010, when increasing medical demand and a few idiosyncratic shocks lead to a blood shortage. In comparison, mobile message calling for existing donors to donate whole blood at a time of shortage has been used throughout our data period, dating back to as early as September 3, 2010. There are two blood type-specific shortage messages for whole blood: one was specific to type B (2012/10/8), one was specific for blood types A and B (2010/9/3). The two messages specific to blood type(s) allows us to construct control individuals who were omitted from some messages but have the same demographics as those receiving these messages.

The bottom of Table 2 shows the distribution of donation amount and blood quality: donation amount is dispersedly distributed between 200 and 400ml, with greater density for 301$400 \mathrm{ml}(42.70 \%)$ and $201-300 \mathrm{ml}(33.57 \%)$ than at or below $200 \mathrm{ml}(23.73 \%)$. Blood quality is generally good: $95.69 \%$ passed a battery of blood tests for HIV, hepatitis, syphilis, and other diseases.

The rest of Table 1 and Table 2 summarizes the data according to whether a donor received any treatment message and whether a donor made any FR donation. By headcount, 10,960 donors received at least one of the two shortage messages specific to blood type and never donated FR throughout. Compared to the full sample of donors, they are slightly more likely to be young, female, single, local and without a college degree. By definition, shortage messages were only sent to existing donors. Among the 10,960 message recipients during the sample period, 7,457 have donated once before getting the message, 1,887 have donated twice, and 1,616 have donated three or more times donated three or more times.

Turning to the 18,324 donors that had ever made FR donation, the majority of them $(17,276)$ never donated anything before their FR donation. We refer to them as no-history FR 
donors. The rest of the FR donors $(1,048)$ are all existing donors, among whom 654 donated once before making the FR donation, 200 donated twice, and 194 donated three or more times. Compared to all donors or those receiving the shortage message, FR donors, especially the nohistory FR donors, are older and more likely to be local and married. This suggests that FR attracts very different types of populations compared to the shortage message or voluntary donation in general.

Consistent with the literature (Goette and Stuzer 2008, Lacetera et al. 2012), we did not find negative evidence on blood safety. The blood quality is comparable between FR and voluntary donors (96.08\% vs $95.67 \%)$, although the quality of no-history FR donations $(95.74 \%)$ is slightly lower than that of existing FR donations (97.97\%). Those who received a shortage message also donate blood of similar quality (97.68\%), compared to other donors. Both FR donors and the treatment message recipients donate a greater amount per episode than the rest of the sample, probably because they know some of their donations target an immediate shortage. We do not often observe the same individual receiving two treatment messages (501), making more than one FR donation (87), or receiving any of the two treatment messages and donating FR anytime throughout the sample (89). We delete these donors from analysis.

\subsection{Matching}

\subsubsection{Matching for message recipients}

Donor motives are hard to observe. A large part of unobserved donation motives may be captured by donation history, in additional to age, gender, or other observable attributes. Thus, we match treated and control individuals by both demographics and donation history. By donation history, we mean the timing and channel of past donations, where timing is defined by a calendar half year, and donation channel is defined by whether a voluntary donation took place at a street mobile (so-called individual donation) or at a dedicated blood drive at the donor's work place (socalled group drive).

For a shortage message, we define treated and control individuals as follows. The two shortage messages we focus on are specific to types A and B (2010/9) and type B (2012/10), hence we define the treated as those that received one of the messages. We exclude those receiving both messages from the analysis, to ensure that we identify the effect of receiving one message. For clean comparison, we search for controls only in the pool of donors whose blood type is either $\mathrm{AB}$ or $\mathrm{O}$. To avoid any cross effect between shortage message and FR donation, both treated and controls are conditional on not making any FR donation throughout our sample period. We treat the recipient of the two treatment messages as exogenous conditional on 
observables, because the blood bank uses an automated marketing software to choose message recipients and the software only allows selection on a few observable variables including blood type, total number of past donations, the timing of last donation, and previous test result.

More specifically, to search for all controls that have the same demographics and donation history as a treated donor, we perform the matching algorithm in two steps. First, for individual $i$ in a calendar half year $t$, we define a variable $d_{i t}$ equal to 1 if he/she made an individual donation at $t, 2$ if he/she made a group donation, and 0 if he/she did not donate. Then for an individual $j$ in the pool of potential controls, we define the Euclidean distance between $i$ and $j$ as

$$
\mathrm{ED}_{\mathrm{ij}}=\left[\sum_{\mathrm{t}=\mathrm{p}}^{\mathrm{r}-1}\left(d_{i t}-d_{j t}\right)^{2}\right]^{1 / 2}
$$

where $p$ is the start of our sample period and $r$ is the half year in which the treated individual received a treatment message. To be conservative, we focus on the pool of controls with zero distance to the treated $\left(\mathrm{ED}_{\mathrm{ij}}=0\right)$. In the second step, among those with zero distance, we search for donors that share the same gender, age (18-21, 22-25, 26-30, 31-40, and 40+), education (bachelor degree or not), marital status (married or not) and hukou location (in the city, elsewhere in the same province, other province, or unknown) with the treated donor.

For the second treatment message (specific to type B), it is possible that a treated donor received other non-blood-type-specific shortage message(s) in January 2010 before this treatment. Therefore, for donors subject to this treatment, we also match the controls by whether they received the same non-treatment shortage message(s) in January 2010. It turns out that any treated donors that also received non-treatment message(s) in January 2010 cannot find a zerodistance match at all, which implies that they are excluded from the message-analysis sample.

The first two rows of Table 3 summarize the count of treated and control donors for the two message treatments. Specifically, 3,102 donors received the message specific to blood types $\mathrm{A}$ and $\mathrm{B}$, and we can find at least one zero-distance controls for 1,749 of them. Another 7,858 donors received the B-specific message, of which 6,291 have zero-distance controls. On average, each treated donor receiving a shortage message has 4 to 5 control donors.

\subsubsection{Matching for FR donors}

A similar matching algorithm applies to the FR treatment. Any individual that made one FR donation throughout our sample period is defined as a treated donor. Those who donated FR more than once, or donated FR once and received any of the two shortage messages are excluded from the analysis. A treated donor may be an existing FR donor or a no-history FR donor. 
For an existing FR donor who donated voluntarily before the FR donation, we search in our database of donors for those who have exactly the same donation history and demographics before the treatment half year. The matching algorithm is the same as above.

For a no-history FR donor $i$, there are two types of controls. The first type includes those who did not donate before the half year of the FR event but donated voluntarily at or after the event time. We can find them in our donor database by the above matching algorithm. Let us refer to them as type- 1 control and denote their count as $N_{1 i}$. The second type of control includes those who never donated to the blood bank throughout our sample period. By definition, they do not appear in our database of donors. To locate them, we resort to the demographic summary from the 2005 census of the city, which tells us the percentage of city residents $\left(S_{2 i}\right)$ that have the same age, gender, education, marital status and hukou location as $i .{ }^{11}$ Assuming the composition of demographics is stable over time, we first calculate the number of city residents in that $i$ 's demographic cell at time $t$ as $N_{2 i t}=\operatorname{Pop}_{t} * S_{2 i}$ and then calculate the number of people in the cell that was at the city at the FR time but may have migrated out of the city at or before time $t$ $\left(N_{2 i t}^{\text {out }}\right) .{ }^{12}$ It is important to count the emigrants in the control group because the treated individuals could have moved out of the city after the FR donation but remain in the bank's database. ${ }^{13}$ Within $N_{2 i t}+N_{2 i t}^{\text {out }}$, some may have donated to the blood bank before the treated FR time (regardless of whether their donation is FR or not); let us denote their count as $N_{0 i}$. Then the count of type- 2 control for $i$ can be expressed as $N_{2 i t}+N_{2 i t}^{o u t}-N_{0 i}-N_{1 i}$. Although these people do not appear in our database of donors, we add them back to the database by imputing their donation dummy at each half year as zero.

Of the 17,276 no-history FR donors, the majority $(17,171)$ have valid type-1 control donors, with on average 7 type- 1 controls per treated donor. The number of type- 2 controls is on average 175,341 per treated donor at the event half year (the median is 62,283). Compared to nohistory FR donors, the matching rate is lower for existing FR donors, especially if they had already donated multiple times before the FR donation. This is not surprising because in total only $4.5 \%$ of the $8+$ million population of the city have ever donated to the blood bank. In total,

\footnotetext{
${ }^{11}$ We are grateful to Chong Liu at Tsinghua University for providing the count of population by demographics.

${ }^{12}$ We estimate each year's cell-specific emigration rate according to the question "How long have you been away from your hukou place?" as recorded in the 2005 census. Because we can only access the 2005 census through a random sample, we pool certain demographic cells so that we have enough observations to calculate the emigration rate. The adjustments only apply to those cells without local residential permits. The total population for a specific cell is accumulated over time

${ }^{13}$ Excluding the emigrants does not affect our qualitative results on FR donation but increases the magnitude of our key estimates. We believe that part of that magnitude is driven by emigrants, so the reported results including emigrants are more conservative and precise.
} 
out of 1,048 existing FR donors, we are able to find controls for 827 of them, with an average of 102 controls per treated donor.

In terms of demographics, no-history FR donors are different from both message recipients and existing FR donors. In particular, no-history FR donors are more likely to be middle-aged, married, and male. People with different donation history before the message or FR treatment are also different in demographics: typically, those who had a longer donation history before treatment are younger and more likely male, college-educated and with hukou within the same province. Given these differences in observable demographics, we believe donors with different donation history may differ in unobservable attributes as well, some of which (e.g. the warm feeling from donation) could trigger different responses to our message or FR treatment.

\section{Estimation Results}

In this section, we present the regression results regarding the effects of the two treatments. The first two subsections focus on donation rate and donation amount in response to shortage message and FR donations separately. Given the WHO concerns about blood quality, results related to blood quality are presented at the end of this section.

\subsection{Effects of shortage messages on donation rate and donation amount}

Figure 3 contrasts the donation rate of message recipients and their controls, by every half calendar year. Time 0 is defined as the half year in which the message was sent. Because different message recipients may end up having a different number of controls in our analysis sample, we weight each control equally within each treatment-control pair and ensure that the total weight is one for the controls as a whole (as opposed to one for the treated donor). By definition, treated and control donors follow an identical path of donation before time 0 , which declines before time 0 partly because of natural attrition (e.g. some donors may have left the city permanently), partly because one is not eligible to donate until the last donation time is at least six months ago. At time 0 , treated donors have a slightly higher donation rate than the controls but the two become identical since time 1 . This suggests that some treated donors responded to the shortage message almost immediately, and this positive effect exists only in the short run (dropping to zero soon after receiving the message).

Table 4 presents the same finding in a regression form. Starting with our matched sample of treated and controls, we collapse the controls of each donor into one observation every halfyear so that the final regression sample is grouped by one treated and one (average) control per 
pair per half-year. ${ }^{14}$ The unit of observation is donor by half-year, the dependent variables are the dummy of donating or not in Columns 1-3 and the amount of donation (zero if not donate) in Columns 4-6. Both regressions are OLS with donor fixed effects and half-year fixed effects. Throughout the whole matched sample, shortage message motivates a 1.8 percentage point increase in donation rate at $\mathrm{t}=0$ and nothing afterwards. This amounts to $5.9 \mathrm{ml}$ more blood per treated donor at $\mathrm{t}=0$ and insignificant change of donation rate at $\mathrm{t}>0$.

The effect of a shortage message can represent a combination of 'ask' effect ( including social pressure and emphathy, see DellaVigna et al. 2012 and Andreoni and Rao 2011) and a shortage-induced warm glow. However, we believe the positive increase is mostly explained by shortage awareness for three reasons. First, as discussed in the literature (DellaVigna et al. 2012), messages and mail solicitation are in general considered low-pressure approaches, compared to high-pressure approaches such as door-to-door fundraising, phone calls, and charity banquets. Second, previous studies have examined the effect of a mailed flyer with information only about blood donation but find no significant increase in voluntary donation (Iajya et al. 2013). Third, in a separate study, the same blood bank conducted a large randomized field experiment in 2014 involving 80,000 participants. One treatment in that experiment was sending existing donors a simple reminder message that requests donation but does not mention a shortage. Compared to a control group with no message, Sun, Gao and Jin (2015) find that sending out a simple reminder message leads to only a 0.275 percentage point increase in donation rate. To the extent that the effect of "asking" is comparable between that experiment and the shortage messages studied here, the much larger effect we found in the shortage messages ( $1.8 \%$ versus $0.275 \%)$ is likely driven by the emphasis on the shortage. This suggests that informing donors of a shortage is an important tool to induce a warm glow and increase donations.

The rest of Table 4 shows the heterogeneous effect of shortage messages. If we split the sample by whether the treated donor donated once (infrequent) or more than once (repeat) before receiving a shortage message, the message has a much bigger effect on repeat donors $(4.2 \%$ increase in donation rate, roughly $15.64 \mathrm{ml})$ than on infrequent donors $(1.3 \%, 3.88 \mathrm{ml})$. As discussed in the literature (Lacetera et al. 2014), the fact that frequent donors donate more even before the message suggests they might derive more of a warm glow from donation and/or face a lower donation cost. Since shortage information does not change donation cost, one likely explanation is that shortage generates more of a warm glow for frequent donors. Consistently, because a shortage is specific to the message time, we find no long-run effect of the shortage

\footnotetext{
${ }^{14}$ We take the average during the collapse operation. Results are identical if we weight individual controls rather than collapse the controls. In particular, in that weighted regression, if a treated donor has $\mathrm{M}$ controls, each control donor receives $1 / \mathrm{M}$ weight so that each treatment-control pair receives the same weight in the regression.
} 
message either on repeat donors or infrequent donors. In other words, the shortage message does not generate a long-lasting warm glow, nor does it crowd out donations in the future. In an unreported table, we also rerun Table 4 for the two shortage messages separately. Both shortage messages motivate an increase in donation rate at $\mathrm{t}=0$ and nothing afterwards. The magnitude of the increase in donation rate is $1.2 \%(\mathrm{p}=0.156)$ for the first message and $1.9 \%(\mathrm{p}<0.001)$ for the second one. The estimates are similar in magnitude, but only statistically significant for the second message, probably because that message involves many more treated donors in our aftermatch sample $(6,291$ versus 1,749$)$.

Finally, it is interesting to compare the effects of a shortage message with that of economic incentives (Lacetera et al. 2014, Sun et al. 2015). The positive effect of a shortage message at the aggregate level is sizable (1.8\%), compared to the reported increase $(0.8 \%)$ for a $\$ 15$ dollar gift in Lacetera et al. 2014. Consistent with the literature, we also find a larger increase for individuals who donated more often; such a differential effect is expected since experienced donors can gain more warm glow from donating at the time of shortage and may have lower cost of time (Lacetera et al. 2014).

\subsection{Effects of FR on donation rate and donation amount}

As articulated in Section 2, it is more challenging to evaluate the causal effect of FR donation on an FR donor's future donation incentives and the blood bank's total blood supply. In particular, because FR donors might be a selected group, as discussed in section 2. Our model can help tease out such a selection effect.

Figure 4 compares the donation rate of FR donors and their controls in the raw data. As in Figure 3, controls are weighted so that we give the same weight to each treated donor and all of his/her controls combined. Time zero denotes the time of each FR donation, and the unit of time is defined as a half calendar year. At time zero, the FR donation rate is one by definition, but the donation rate of the control donors is much lower. Given the demographic difference between nohistory and existing donors, we present Figure 4 for no-history and existing FR donors separately. The donation rate of no-history donors jumps back to nearly zero right after the FR donation, which is below the donation rate of their corresponding controls at $\mathrm{t}=1$ but comparable to the controls at $t>=2$. One possible explanation is that the experience of FR donation triggered distrust or crowd-out effects among no-history FR donors.

The picture for the existing FR donors presents quite a contrast. By construction, these FR donors and their controls have the same donation history before time 0 . Both groups had a dip at $\mathrm{t}=-1$, because donors are not allowed to donate again until six months after the last donation. At 
time 0 , the FR donors donated 100\% (by definition), while less than $10 \%$ of their controls donated voluntarily. After time 0 , the FR donors continue to have a slightly higher donate rate than their controls, and this difference seems to persist from $t=1$ to $t=5$ (i.e. more than two years and half). One potential explanation is selection: the existing donors that agree to donate FR may donate anyway even without the FR program. If this is the case, FR donations from these donors have little effect on the bank's current and future blood supply. Another explanation is that the warm glow generated by the FR experience dominates the potential negative effects (distrust and crowd-out) in the long run, encouraging the existing FR donors to donate even more in the future. This could have a beneficial effect on future blood supply, even if the FR donors are a selected group.

Regression results are presented in Tables 5 and 6 . Table 5 presents the differences-indifferences results for no-history and existing FR donors separately, without controlling for potential selection in the acceptance of FR request. Table 6 controls for selection. In all tables, we use ordinary least square regressions and the dependent variable is whether a donor donates in a particular half calendar year ${ }^{15}$.

The first three columns of Table 5 focus on no-history FR donors. Recall that we have two types of controls for them: type- 1 control donors did not donate before $t=0$, but donated at or after $\mathrm{t}=0$; type- 2 control donors are the part of the city population that have the same demographics as a no-history FR donor but never donated whole blood throughout our data period. To include both types of controls, we first collapse controls per treated donor into one observation per half-year and then run the OLS regression with donor fixed effects and half-year fixed effects. Column 1 shows that FR generated close to one donation at $t=0(0.729$, driven by definition of FR donors) and 0.055 fewer donations per half year after $\mathrm{t}=0$. Column 2 further breaks down the post-FR period into $t=1, t=2$ and $t>=3$. The negative effect at $t=1$ is bigger than the other two periods (-8.8\% versus $-4.5 \%$ and $-3.3 \%)$, which is understandable as there is a natural attrition after a donation, and even regular donors may prefer to donate once a year rather than twice a year. Translating the effect on donation rate into donation amount, Column 3 shows that the FR treatment generates $245.6 \mathrm{ml}$ more blood supply per donor at $\mathrm{t}=0$, and $17.8 \mathrm{ml}$ less per donor per half-year after $\mathrm{t}=0$.

The last three columns of Table 5 report the parallel regression results for existing FR donors. Column 4 shows a large positive coefficient for existing FR donors at $t=0(0.958$, driven by definition). Contrary to the case for no-history FR donors, the coefficient for existing FR

\footnotetext{
${ }^{15}$ We did not use a duration model for estimation because a duration model does not allow us to control for timeinvariant unobserved factors across donors. Moreover, it is sensitive to the choice of the distribution for a survival model to fit.
} 
donors after $t=0$ is positive $(2.9 \%)$. Column 5 decomposes the post-event period into $t=1, t=2$ and $\mathrm{t}>=3$. It shows that the positive effect on FR donors is $2.1 \%$ at $\mathrm{t}=1$, becomes stronger at $\mathrm{t}=2$ (4.7\%) and then comes back to $2.2 \%$ at $\mathrm{t}>=3$. The stronger effect at $\mathrm{t}=2$ than $\mathrm{t}=1$ can be explained by the fact that many repeat donors donate once a year and therefore there is a natural attrition half a year after the last donation. The positive effect at $t>=3$ suggests a long-lasting effect of FR encouraging existing FR donors to donate more in the future. The last column of Table 6 shows that the positive effect of FR on existing FR donors creates $332.2 \mathrm{ml}$ blood supply per donor at $\mathrm{t}=0$ and $10.3 \mathrm{ml}$ extra blood supply per half-year per donor after $\mathrm{t}=0$.

The positive long-run effect of FR on existing donors is an interesting contrast to the lack of long-run effect from shortage messages. This is possible because giving blood to a close social connection may create an extra warm glow (Fong and Luttmer 2009) and the close tie with the patient during and after patient recovery could reinforce that warm glow in the long run. This strong warm glow can also dominate distrust and crowd-out in the long run.

To distinguish selection from the true FR effect on future blood supply, Table 6 follows the econometric structure presented in Section 2. The first two columns look at donation rate and donation amount for no-history FR donors; the last two columns look at the same dependent variables for existing FR donors. As we expect, there is a significant selection effect among existing FR donors, while the selection effect for no-history FR donors is close to non-existent. This is probably because we have more variations in the fraction of donors donating voluntarily at time zero $(\lambda)$ among the controls of existing FR donors than among the controls of no-history FR donors. In particular, the selection coefficient $\left(\Delta \theta=\frac{\theta_{V}}{\theta_{N}}\right)$, which is defined as the ratio between the likelihood of type $\mathrm{V}$ donors accepting the FR request versus the likelihood of type $\mathrm{N}$ accepting, turns out to be $0.111 / 0.063=1.76$ for existing FR donors, with a p-value between 5\% and $10 \%$. If we assume $\theta_{V}=1$ (because type $\mathrm{V}$ donors are defined to be willing to donate at time 0 even without an FR request), this number implies that type $\mathrm{N}$ donors will donate with a likelihood $\theta_{N}=56.76 \%$ upon an FR request. We will use this number to conduct a back-ofenvelope calculation of the effect of FR on the total blood supply. In comparison, for no-history FR donors, Table 6 shows a slightly negative but statistically zero difference in the voluntary donation rate of type- $\mathrm{V}$ and type-N people $(\Delta p)$, which suggests little selection and makes it meaningless to calculate $\Delta \theta$ from the estimates of $\Delta p \cdot \Delta \theta$ and $\Delta p$. In light of this, our back-ofenvelope calculation will assume different values of $\theta_{N}$ (hence different $\Delta \theta$ as we assume $\theta_{V}=$ 1) for robustness check. 
After isolating the selection effect, the rest of Table 6 shows that the causal effect of FR on future donation rate, or $\omega$, is negative for no-history FR donors (-0.036) but positive for existing FR donors (0.029), which translates into $-11.53 \mathrm{ml}$ less per half-year per no-history FR donor and $10.15 \mathrm{ml}$ more per half-year per existing FR donor. Our study is among the first to identify a significant post-intervention effect for blood donation (Lactera et al. 2013). Very interestingly, we find that there is a motivation loss for those donors who are less pro-social, while there is an increase in voluntary donation for donors who are overall more pro-social.

\subsection{Effect of shortage message and FR donation on blood quality}

Defining a quality dummy equal to one if the donated blood passes the standard battery of blood tests, Table 7 regresses this dummy on the treatment status by $t=0$ and $t>0$ separately for each treatment group (message treatment, no-history FR donors, and existing FR donors). We choose to run the regression for $\mathrm{t}=0$ and $\mathrm{t}>0$ separately because blood quality information is not available until a blood donation exists; hence, any regression on blood quality must be conditional on a subsample of donation dummy equal to one. This subsample may differ by time, which makes the across-time comparison hard to interpret. In light of this, for each particular time period $(\mathrm{t}=0$ or $\mathrm{t}>0)$, the regression gives us a straightforward quality comparison between the treated and control donors, conditional on both donating at the time. Again, we collapse the controls so that each treated and control pair gets the same weight.

Results in Table 7 do not support the WHO's concern about blood quality: for both message recipients and FR donors, there is no significant quality difference between treated and control donors at both $\mathrm{t}=0$ and $\mathrm{t}>0$.

\section{Discussion and Future Research}

In this paper we have shown that both a shortage message and an FR program can mitigate blood shortages in the short run with little compromise of blood quality. However, these methods target different audiences, have different effects in the long run, and affect different donors differently.

From the blood bank's point of view, what are the key tradeoffs between a shortage message and an FR program? We identify four potential tradeoffs for consideration when implementing non-price methods to address shortage. The first tradeoff lies in the extent of control. A blood bank can fully control who receives a shortage message and how many receive it, but the recruitment of FR donors is outsourced to patients. This implies that a shortage message may be more effective if the bank is short of a specific type of blood and the bank has a 
large pool of existing donors to choose from. That being said, a direct message allows less control over timing, as the blood bank cannot force donors to donate at a specific time. In contrast, FR may be more helpful in mitigating the shortage facing a particular patient at a particular time.

The second tradeoff between a shortage message and an FR program relates to their targeted audiences. While a mobile message can easily reach existing donors, it is difficult to reach those who have not donated to the bank already. In theory, the bank could announce a blood shortage on TV, radio, newspaper, or the Internet, but such broadcasting is less targeted and may be crowded out by other information, which introduces more uncertainty and is likely less effective than sending mobile messages to individual donors. In comparison, an FR program relies on individual patients to reach out to their own social connections, which could bring in a large number of donors who may otherwise never donate voluntarily. These no-history individuals may be more willing to donate to their friends or family than to a stranger. As shown in our data, the FR approach indeed brings an additional source of blood supply, which could be more effective in increasing a blood supply quickly when the population of voluntary donors is small and decreasing.

The third tradeoff concerns the differential effects in the short run and long run. Similar to economic incentives, a shortage message is highly effective in the short run but does not increase donation in the long run. Interestingly, an FR program can increase the donation from existing donors in the long run but at the same time lead to a small motivation loss for new donors in the long term. Fortunately, such a decrease for new donors is very small and can be well justified by the selection effect, i.e. additional (one-time) donation from those no-history donors.

Finally, blood banks also need to compare the implementation costs of both programs. As discussed before, FR shifts the burden of donor recruitment from the blood bank to individual patients, which could cut the cost of recruitment by 75 to 87 percent. In contrast, sending a shortage message has a small cost (about 1.2 US dollar/100 messages).

Table 8 summarizes these four tradeoffs in a back-of-envelope calculation. There are three blocks here. The first block follows our data: consider a city with a population of 4 million, of whom $4.5 \%$ are existing donors; each person faces the same chance of needing a blood transfusion in a random half year. If we rely on voluntary donation without any intervention, suppose there is a $1 \%$ shortage rate, where shortage rate is defined as the rate of needing blood transfusion minus the rate of donation. If the bank sends out a shortage message to all existing donors, our estimates suggest that the blood supply can be boosted by 3,240 extra donations within six months of the message delivery but zero effect afterwards. In comparison, if the bank 
requires half of the sick patients facing a shortage to find one FR donation by themselves, the FR program will affect 19,100 individuals who have no donation history at the bank, and 900 individuals who have a donation history at the bank. For existing FR donors, our data suggest $\lambda=0.04$. If we are willing to assume $\theta_{V}=1$, our estimates suggest $\theta_{N}=56.76 \%$. For nohistory FR donors, there are almost no voluntary donors at the particular time of FR. So we assume $\lambda=0$. Because our estimation does not yield a reasonable estimate for the $\theta_{N}$ of nohisotry FR donors, we assume they have the same $\theta_{N}$ as existing donors (56.76\%) in Table 8. Later we will try different $\theta_{N}$ for no-history FR donors.

Under these assumptions, the FR program at $\mathrm{t}=0$ can generate 10841.2 FR donations from no-history donors and 490.4 donations from existing donors. However, based on our estimates of $\omega$ in Table 6 , the no-history donors will reduce 390.3 donations per half-year after FR and the existing FR donors will bring 15.3 more donations per half-year after FR. Summing over the effect for five years (from $t=0$ to $t=9$ ), introducing FR to half of the patients is much more effective in increasing blood supply than sending out a shortage messages to all existing donors (7956.4 vs 3,240 donations). In other words, in order to generate the same effect on the overall blood supply within the next five years, sending out shortage messages to all existing donors is equivalent to introducing the FR to $20.36 \%$ of the sick patients facing a shortage. If the goal is to generate the same blood supply in the short run ( $\mathrm{t}=0$ only), then sending out shortage messages to all existing donors is equivalent to introducing the FR to $14.3 \%$ of the sick patients.

In the second block of Table 8, we change the percent of the donating population to $10 \%$, which reduces the gap between the two methods. If we increase it further to $15 \%$, the shortage message becomes more effective than the FR program in increasing blood supply over five years (the third block of Table 8).

In Table 9, we redo the back-of-envelope calculation for the first block of Table 8 but change the probability of a no-history potential donor taking up the FR request $\left(\theta_{N}\right)$ from $56.76 \%$ to $100 \%$ and $30 \%$. This parameter is important, because it determines the number of donations one could expect from no-history FR donors at $\mathrm{t}=0$. As expected, if every FR request presented to a no-history potential donor can be turned into a FR donation $\left(\theta_{N}=100 \%\right)$, FR is more effective than a shortage message in generating a new blood supply for all three scenarios, no matter whether the voluntary donation rate is as low as $4.5 \%$ or as high as $15 \%$. In comparison, when $\theta_{N}$ is only $30 \%$ (roughly 1 of 3 FR requests will be accepted by no-history FR donors), the effectiveness of FR is reduced, and a shortage message can generate more blood supply when the voluntary donation rate is $10 \%$ or $15 \%$. 
Overall, the back-of-envelope calculation suggests that a shortage message can be used in places where the donor population is large and the shortage is small. In comparison, FR could be more useful when the voluntary donation rate is low, the shortage is severe, and the FR-takeup rate is relatively high among those who never donated before. In this sense, our data suggests a more optimistic picture for FR than the WHO recommendation. However, in a society with a low donation rate (which could be the reason for a severe shortage to begin with), most FR donors will be no-history FR donors, and the FR treatment may discourage voluntary donation in the long run by generating either distrust or crowd-out. Although a broader introduction of FR can generate more blood supply in the short run, it may exacerbate a shortage problem in the long run. Like the WHO, we reach a cautious conclusion about FR programs but for a reason other than quality concerns.

Future research may take several different directions. First, the shortage messages studied in this paper target donors that have donated before. Previous studies have found that an emergency appeal (such as after a disaster) is also effective in driving new donors (Reich et al. 2006, Ryzhov et al. forthcoming). Future studies can extend our work to study the impact of a shortage message on non-donors.

Second, we empirically show that shortage information can have a large and positive effect on blood donation in the short run. This finding has immediate managerial implications for blood banks that wish to alleviate shortages. However, theoretically we cannot differentiate the importance of two potential mechanisms: pure altruism and the warm feeling of doing good for others. Future studies can employ theory-driven lab experiments (Crumpler and Grossman 2008) or field experiments (DellaVigna et al. 2012) to test the underlying mechanisms behind this effect.

Similarly, we identify a significant long-run effect of FR on blood donation; such a long-run effect differs for existing donors and new donors. We believe this interesting evidence can be explained by FR generating a long-lasting warm glow for existing FR donors but distrust or an incentive to save blood for friends and family among no-history FR donors. More studies are needed to confirm this explanation. 


\section{References}

Allain, J. P., Sarkodie, F., Asenso- Mensah, K., \& Owusu- Ofori, S. (2010). Relative safety of first- time volunteer and replacement donors in West Africa. Transfusion, 50(2), 340-343.

Messih, I. Y. A., Ismail, M. A., Saad, A. A., \& Azer, M. R. (2014). The degree of safety of family replacement donors versus voluntary non-remunerated donors in an Egyptian population: a comparative study. Blood Transfusion, 12(2), 159.

Allcott, H. (2011). Social norms and energy conservation. Journal of Public Economics, 95(9), 1082-1095.

Andreoni, J. 1988. "Privately provided public goods in a large economy: the limits of altruism." Journal of Public Economics, 35(1), 57-73.

Andreoni, J., 1989. "Giving with Impure Altruism: Applications to Charity and Ricardian Equivalence.” Journal of Political Economy 97 (6), 1447-1458.

Andreoni, J., 1990. "Impure Altruism and Donations to Public Goods: A Theory of Warm-Glow Giving." The Economic Journal 100 (401), 464-477.

Andreoni, J., \& Rao, J. M. (2011). The power of asking: How communication affects selfishness, empathy, and altruism. Journal of Public Economics, 95(7), 513-520.

Bates I.; Manyasi G.; Medina Lara A. "Reducing replacement donors in Sub-Saharan Africa: challenges and affordability", Transfusion Medicine. 2007 Dec. 17(6): 434-42.

Charness, G., \& Gneezy, U. (2009). Incentives to exercise. Econometrica,77(3), 909-931.

Crumpler,H. and Grossman, P. J. (2008). "An experimental test of warm glow giving." Journal of Public Economics, 92, 1011-1021.

DellaVigna, S. List, J. A., \& Malmendier, U. 2012. "Testing for altruism, and social pressure in charitable giving." Quarterly Journal of Economics, 127(1), 1-56.

Edwards, J. T., \& List, J. A. (2014). Toward an understanding of why suggestions work in charitable fundraising: Theory and evidence from a natural field experiment. Journal of Public Economics, 114, 1-13.

Frey, B. S., \& Meier, S. (2004). Social comparisons and pro-social behavior: Testing" conditional cooperation" in a field experiment. American Economic Review, 1717-1722.

Fischbacher, U., Gächter, S., \& Fehr, E. (2001). Are people conditionally cooperative? Evidence from a public goods experiment. Economics Letters, 71(3), 397-404.

Fong, C. M., \& Luttmer, E. F. (2009). What determines giving to Hurricane Katrina victims? Experimental evidence on racial group loyalty. American Economic Journal: Applied Economics, 1(2), 64.

Goette, L., Stutzer A. (2009) Blood donations and incentives: evidence from a field experiment. IZA Working Paper No. 3580. Available at SSRN: http://ssrn.com/abstract=1158977

Goette, L., Stutzer, A., \& Frey, B. M. (2010). Prosocial motivation and blood donations: a survey of the empirical literature. Transfusion Medicine and Hemotherapy, 37(3), 149-154.

Kessler, J. B., \& Roth, A. E. (2012). Organ Allocation Policy and the Decision to Donate. The American Economic Review, 2018-2047.

Kessler, J. B., \& Roth, A. E. (2014). Getting more organs for transplantation. The American Economic Review, 104(5), 425-430.

Konow, J. (2010). Mixed feelings: Theories of and evidence on giving. Journal of Public Economics, 94(3), 279-297.

Iajya, V., Lacetera, N., Macis, M., \& Slonim, R. (2013). The effects of information, social and financial incentives on voluntary undirected blood donations: Evidence from a field experiment in Argentina. Social Science \& Medicine, 98, 214-223. 
Lacetera, N., \& Macis, M. (2010). "Social image concerns and prosocial behavior: Field evidence from a nonlinear incentive scheme." Journal of Economic Behavior \& Organization, 76(2), 225-237.

Lacetera, N., Macis, M., \& Slonim, R. (2012). Will there be blood? Incentives and displacement effects in pro-social behavior. American Economic Journal: Economic Policy, 186-223.

Lacetera, N., Macis, M., \& Slonim, R. (2013). Economic rewards to motivate blood donations. Science, 340(6135), 927-928.

Lacetera, N., Macis, M., \& Slonim, R. (2014). Rewarding volunteers: a field experiment. Management Science, 60(5), 1107-1129.

Leider, S., Möbius, M. M., Rosenblat, T., \& Do, Q. A. (2009). Directed altruism and enforced reciprocity in social networks. The Quarterly Journal of Economics, 124(4), 1815-1851.

Leider, S., \& Roth, A. E. (2010). Kidneys for sale: Who disapproves, and why?. American Journal of Transplantation, 10(5), 1221-1227.

List, J. A., \& Price, M. K. (2009). The role of social connections in charitable fundraising: Evidence from a natural field experiment. Journal of Economic Behavior \& Organization, 69(2), 160-169.

Martin, R., \& Randal, J. (2008). How is donation behaviour affected by the donations of others?. Journal of Economic Behavior \& Organization, 67(1), 228-238.

Potters, J., Sefton, M., \& Vesterlund, L. (2005). After you-endogenous sequencing in voluntary contribution games. Journal of public Economics, 89(8), 1399-1419.

Reich, P., Roberts, P., Laabs, N., Chinn, A., McEvoy, P., Hirschler, N., \& Murphy, E. L. (2006). A randomized trial of blood donor recruitment strategies. Transfusion, 46(7), 1090-1096.

Roth, A. E., Sönmez, T., \& Ünver, M. U. (2004). Kidney Exchange. The Quarterly Journal of Economics, 457-488.

Roth, A. E., Sönmez, T., \& Ünver, M. U. (2005). A kidney exchange clearinghouse in New England. American Economic Review, 376-380.

Roth, A. E. (2007). Repugnance as a Constraint on Markets. The Journal of Economic Perspectives, 21(3), 37-58.

Ryzhov, I. O., Han, B., Bradic, J., \& Bradic, A. forthcoming. Cultivating disaster donors: A case application of scalable analytics on massive data. Management Science.

Shang, J. and Croson, R. (2008). "The impact of downward social information on contribution decisions", Experimental Economics, vol. 11(3), pp. 221-33.

Shang, J.,\& Croson, R. (2009). "A field experiment in charitable contribution: The impact of social information on the voluntary provision of public goods." The Economic Journal, 119(540), 1422-1439.

Slonim, R., Wang, C., \& Garbarino, E. (2014). The Market for Blood. The Journal of Economic Perspectives, 177-196

Sun, T.; Gao, G., \& Jin, G. Z. (2015): Motivating Group Donation: Evidence from a Large Field Experiment, Working Paper.

Stutzer, A., Goette, L., \& Zehnder, M. (2011). Active Decisions and Prosocial Behaviour: a Field Experiment on Blood Donation. The Economic Journal, 121(556), F476-F493.

World Health Assembly (WHA 1975) 28.72 "Utilization and supply of human blood and blood products" Twenty-Eighth World Health Assembly, Geneva 13-30 May 1975, Accessed at http://www.who.int/bloodsafety/en/WHA28.72.pdf?ua=1on January 29, 2015.

World Health Organization (WHO 2014) "Blood Safety and Availability", fact sheet \#279, updated June 2014, http://www.who.int/mediacentre/factsheets/fs279/en/.

World Health Organization (WHO 2009) "Global consultation: 100\% voluntary non-remunerated donation of blood and blood components", Melbourne, 9-11 June 2009. Accessed at http://www.who.int/bloodsafety/ReportGlobalConsultation2009onVNRBD.pdf?ua=1 on January 29, 2015. 
Figure 1: World map of donation rate

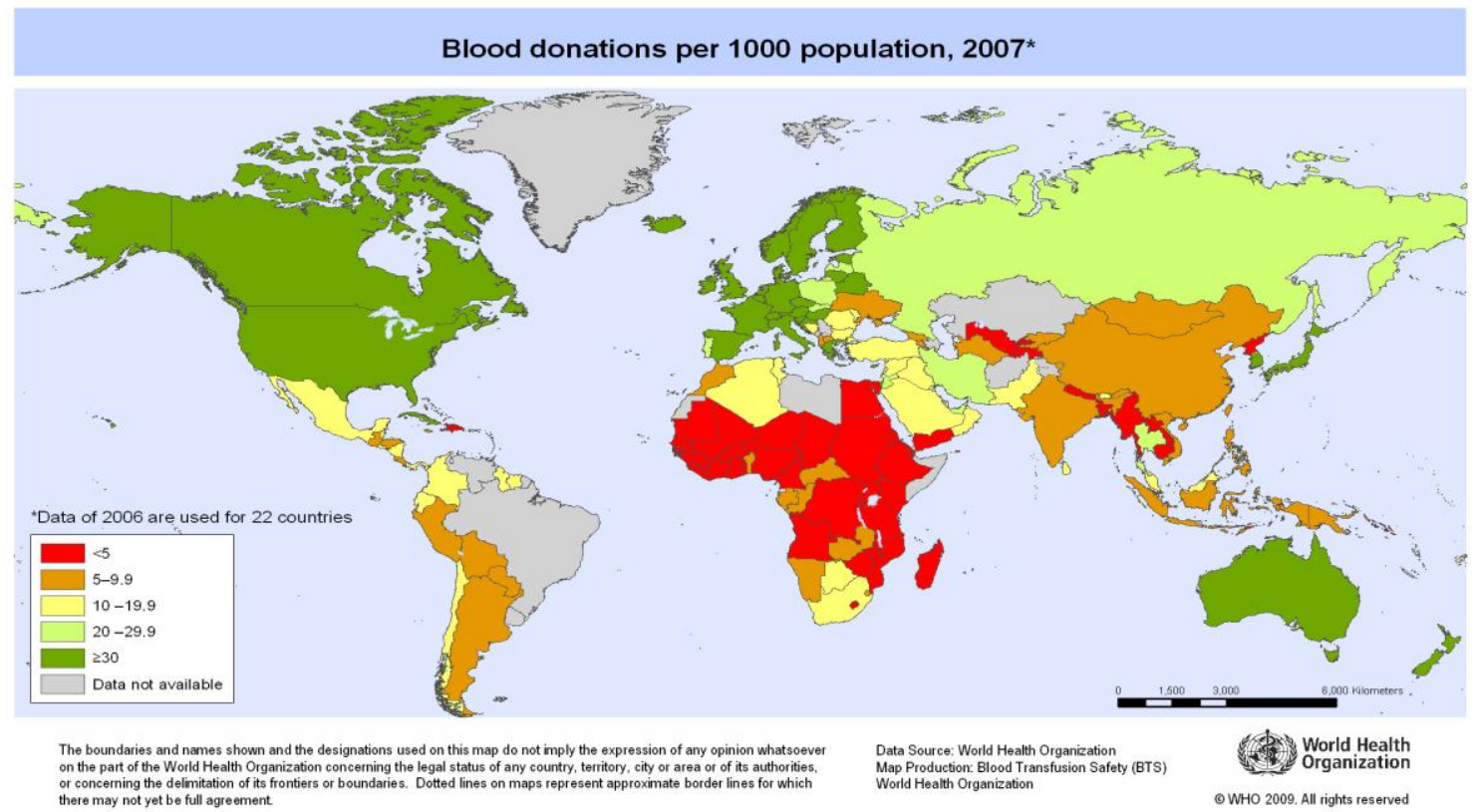

Figure 2:

Trends in the Number of Blood Donations by Donation Type

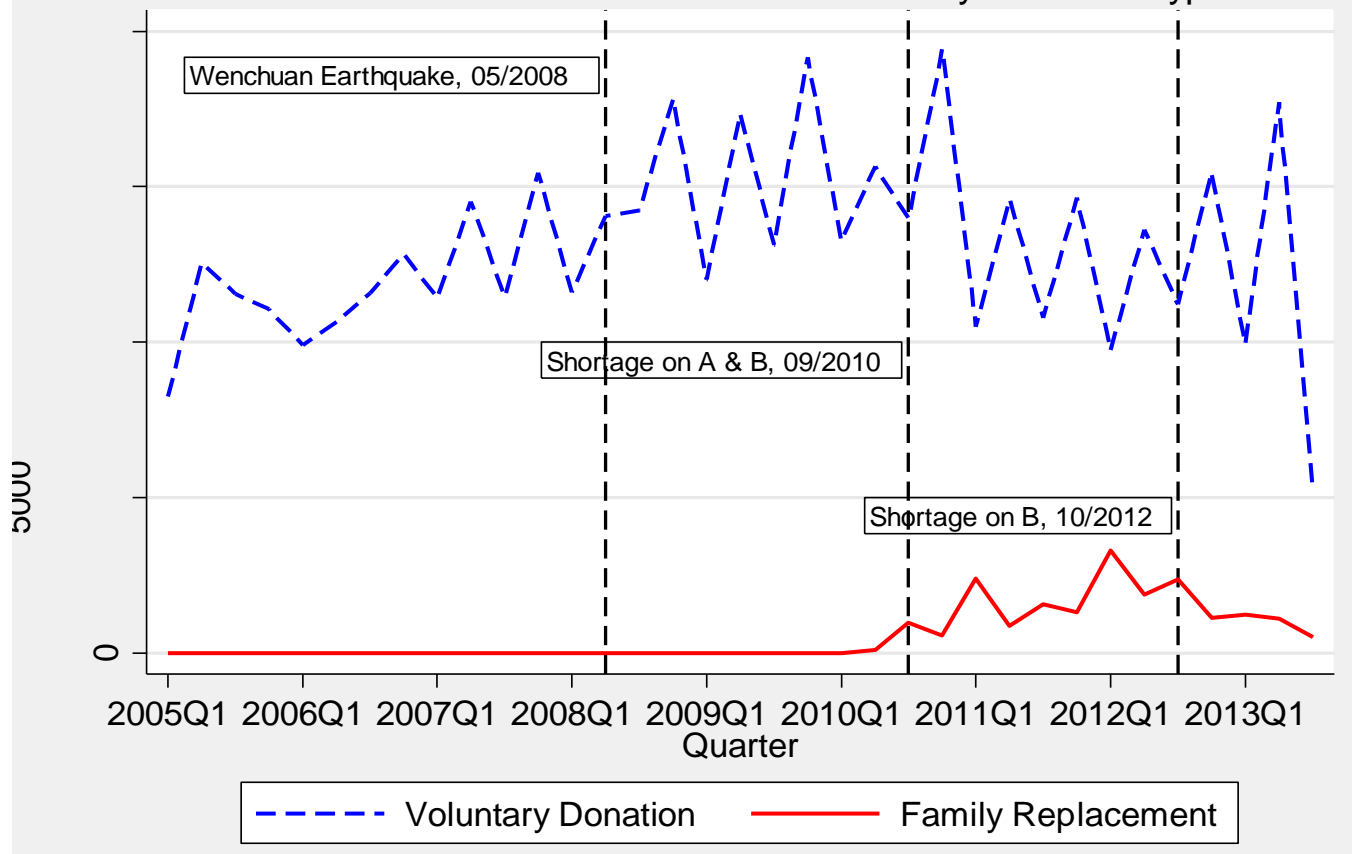


Figure 3: Donation rate by treated and control donors, upon receiving a shortage message $(\mathrm{t}=0$ refers to the time of receiving a treatment message.)

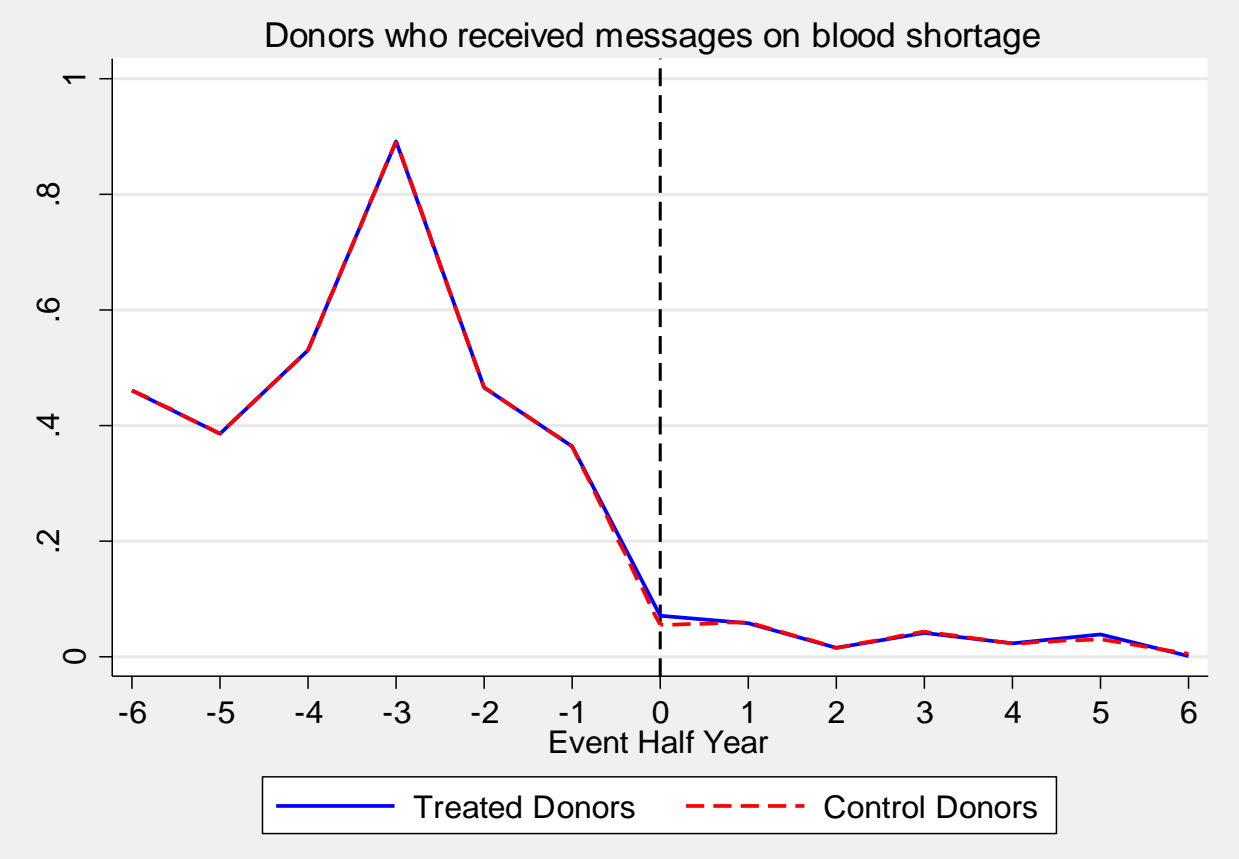

Figure 4: Donation rate by treated and control donors, upon FR donation $(\mathrm{t}=0$ refers to the timing of making an FR donation.)
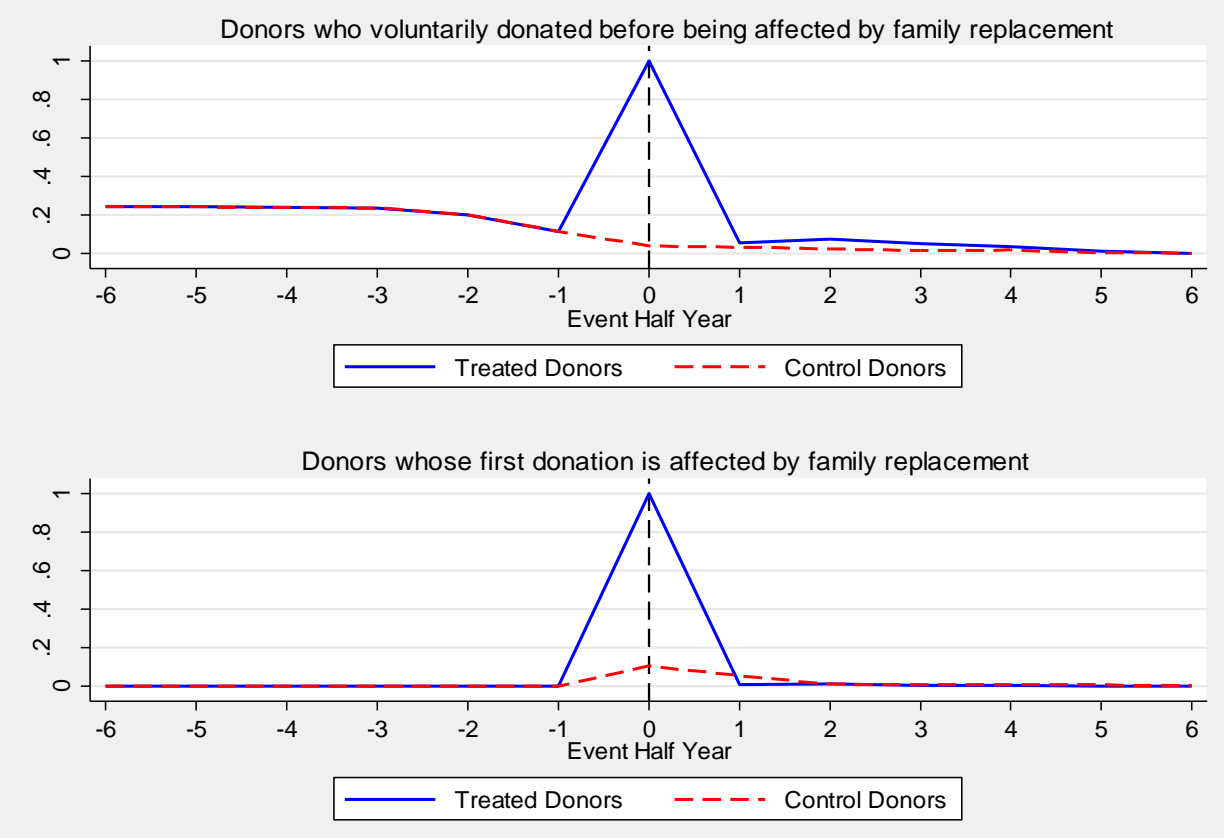
Table 1: Headcount

\begin{tabular}{|c|c|c|c|c|c|c|c|c|c|}
\hline & \multicolumn{3}{|c|}{ Total Counts of Donors } & \multirow{2}{*}{\multicolumn{2}{|c|}{$\begin{array}{c}\text { Received Messages } \\
\begin{array}{c}\text { Never affected } \\
\text { by FR }\end{array}\end{array}$}} & \multicolumn{4}{|c|}{ Have ever donated FR } \\
\hline & \multirow{2}{*}{ Count } & \multirow{2}{*}{$\%$ in sample } & \multirow{2}{*}{$\begin{array}{c}\% \text { in } \\
\text { population }\end{array}$} & & & \multicolumn{2}{|c|}{$\begin{array}{l}\text { Have donated } \\
\text { before FR }\end{array}$} & \multicolumn{2}{|c|}{$\begin{array}{c}\text { Never donated } \\
\text { before FR }\end{array}$} \\
\hline & & & & Count & $\%$ in sample & Count & $\%$ in sample & Count & $\%$ in sample \\
\hline Total & 335,913 & & & 10,960 & & 1,049 & & 17,276 & \\
\hline Not Married & 106,300 & $31.67 \%$ & $16.76 \%$ & 3,976 & $36.28 \%$ & 282 & $26.88 \%$ & 2,863 & $16.57 \%$ \\
\hline Married & 229,533 & $68.33 \%$ & $83.24 \%$ & 6,984 & $63.72 \%$ & 767 & $73.12 \%$ & 14,413 & $83.43 \%$ \\
\hline Male & 204,406 & $60.85 \%$ & $49.05 \%$ & 6,293 & $57.42 \%$ & 657 & $62.63 \%$ & 11,640 & $67.38 \%$ \\
\hline Female & 131,507 & $39.15 \%$ & $50.95 \%$ & 4,667 & $42.58 \%$ & 392 & $37.37 \%$ & 5,636 & $32.62 \%$ \\
\hline College Degree & 66,443 & $19.78 \%$ & $22.78 \%$ & 1,392 & $12.75 \%$ & 187 & $17.83 \%$ & 1,979 & $11.46 \%$ \\
\hline No College Degree & 269,470 & $80.22 \%$ & $77.22 \%$ & 9,563 & $87.25 \%$ & 862 & $82.17 \%$ & 15,297 & $88.54 \%$ \\
\hline Local Hukou & 65,004 & $19.35 \%$ & $78.66 \%$ & 2,689 & $24.53 \%$ & 428 & $40.80 \%$ & 4,989 & $28.88 \%$ \\
\hline Same-province Hukou & 126,106 & $37.54 \%$ & $13.46 \%$ & 3,889 & $35.48 \%$ & 338 & $32.22 \%$ & 5,593 & $32.37 \%$ \\
\hline Other-Province Hukou & 99,747 & $29.69 \%$ & $7.88 \%$ & 4,252 & $38.80 \%$ & 274 & $26.12 \%$ & 4,090 & $23.67 \%$ \\
\hline Unknown & 45,056 & $13.41 \%$ & $0.00 \%$ & 130 & $1.19 \%$ & 9 & $0.86 \%$ & 2,604 & $15.07 \%$ \\
\hline$[18,21]$ & 106,380 & $31.67 \%$ & $7.41 \%$ & 3,976 & $36.28 \%$ & 282 & $26.88 \%$ & 2863 & $16.57 \%$ \\
\hline$[21,25]$ & 109,509 & $32.47 \%$ & $8.73 \%$ & 2,496 & $22.77 \%$ & 259 & $24.69 \%$ & 2,431 & $14.07 \%$ \\
\hline$(25,30]$ & 53,333 & $15.88 \%$ & $10.01 \%$ & 1,613 & $14.72 \%$ & 190 & $18.11 \%$ & 2,947 & $17.06 \%$ \\
\hline$(30,40]$ & 45,095 & $13.42 \%$ & $24.99 \%$ & 1,948 & $17.77 \%$ & 192 & $17.80 \%$ & 5,381 & $31.15 \%$ \\
\hline Above 40 yrs & 22,046 & $6.56 \%$ & $48.86 \%$ & 927 & $8.46 \%$ & 126 & $11.70 \%$ & 3,654 & $21.15 \%$ \\
\hline
\end{tabular}


Table 2: Summary of donation episodes

\begin{tabular}{|c|c|c|c|c|c|c|c|c|}
\hline \multirow[b]{3}{*}{ Total } & & & \multirow{2}{*}{\multicolumn{2}{|c|}{$\begin{array}{l}\text { Received Messages } \\
\text { Never affected by FR }\end{array}$}} & \multicolumn{4}{|c|}{ Have ever donated FR } \\
\hline & \multicolumn{2}{|c|}{ Total Counts } & & & \multicolumn{2}{|c|}{$\begin{array}{c}\text { Have donated } \\
\text { before FR } \\
\end{array}$} & \multicolumn{2}{|c|}{$\begin{array}{c}\text { Never donate } \\
\text { before FR } \\
\end{array}$} \\
\hline & 447,357 & $100(\%)$ & 20,548 & $100(\%)$ & 3,147 & $100(\%)$ & 17,642 & $100(\%)$ \\
\hline \multicolumn{9}{|l|}{ Blood donation type } \\
\hline Individual voluntary & 257,150 & 57.48 & 18,742 & 91.21 & 1,699 & 53.99 & 317 & 1.80 \\
\hline Group voluntary & 171,706 & 38.38 & 1,806 & 8.79 & 399 & 12.69 & 49 & 0.28 \\
\hline $\mathrm{FR}$ & 18,501 & 4.14 & 0 & 0.00 & 1,049 & 33.33 & 17,276 & 97.93 \\
\hline \multicolumn{9}{|l|}{ Donation amount } \\
\hline$<=200 \mathrm{ml}$ & 106,159 & 23.73 & 1,634 & 7.95 & 389 & 12.36 & 3,010 & 17.06 \\
\hline$>200 \mathrm{ml}$ and $<=300 \mathrm{ml}$ & 150,185 & 33.57 & 5,408 & 26.32 & 904 & 28.73 & 5,305 & 30.07 \\
\hline$>300 \mathrm{ml}$ and $<=400 \mathrm{ml}$ & 191,013 & 42.70 & 13,506 & 65.73 & 1,854 & 58.91 & 9,327 & 52.87 \\
\hline \multicolumn{9}{|l|}{ Blood Quality } \\
\hline Passed quality test & 428,075 & 95.69 & 20,072 & 97.68 & 3,082 & 97.97 & 16,890 & 95.74 \\
\hline
\end{tabular}


Table 3: Summary of treated and control

\begin{tabular}{|c|c|c|c|c|c|c|c|c|c|c|}
\hline & \multirow{2}{*}{$\begin{array}{c}\begin{array}{c}\text { Before } \\
\text { Matching }\end{array} \\
\text { Treated }\end{array}$} & \multicolumn{9}{|c|}{ After Matching } \\
\hline & & Treated & Control & Married & Male & College & Age & Local & $\begin{array}{l}\text { Same } \\
\text { Prov }\end{array}$ & $\begin{array}{l}\text { Other } \\
\text { Prov }\end{array}$ \\
\hline Shortage on A and B & 3,102 & 1,749 & 8,474 & 0.56 & 0.55 & 0.15 & 25.33 & 0.24 & 0.38 & 0.36 \\
\hline Shortage on B & 7,858 & 6,291 & 29,670 & 0.59 & 0.59 & 0.10 & 25.73 & 0.20 & 0.35 & 0.44 \\
\hline First Donation as FR & 17,276 & 17,171 & 92,423 & 0.84 & 0.67 & 0.11 & 31.84 & 0.29 & 0.32 & 0.24 \\
\hline Second Donation as FR & 654 & 654 & 82,770 & 0.70 & 0.63 & 0.19 & 26.90 & 0.39 & 0.32 & 0.27 \\
\hline Third Donation as FR & 200 & 151 & 1,673 & 0.64 & 0.62 & 0.12 & 27.05 & 0.32 & 0.38 & 0.30 \\
\hline Fourth Donation as FR & 97 & 21 & 41 & 0.59 & 0.66 & 0.12 & 28.17 & 0.22 & 0.56 & 0.22 \\
\hline 4+ Donation as FR & 97 & 1 & 1 & 0.00 & 1.00 & 0.00 & 19.00 & 0.00 & 0.00 & 1.00 \\
\hline Total of Ever Donated as FR & 18,324 & 17,998 & 176,908 & 0.68 & 0.63 & 0.17 & 26.96 & 0.38 & 0.34 & 0.28 \\
\hline
\end{tabular}

Note: * For those whose first donation is FR, the number of controls refer to type 1 control. The average type 2 control is 175,341 at the time of FR, the median is 62283 . 
Table 4: Effects of shortage message on donation rate and donation amount

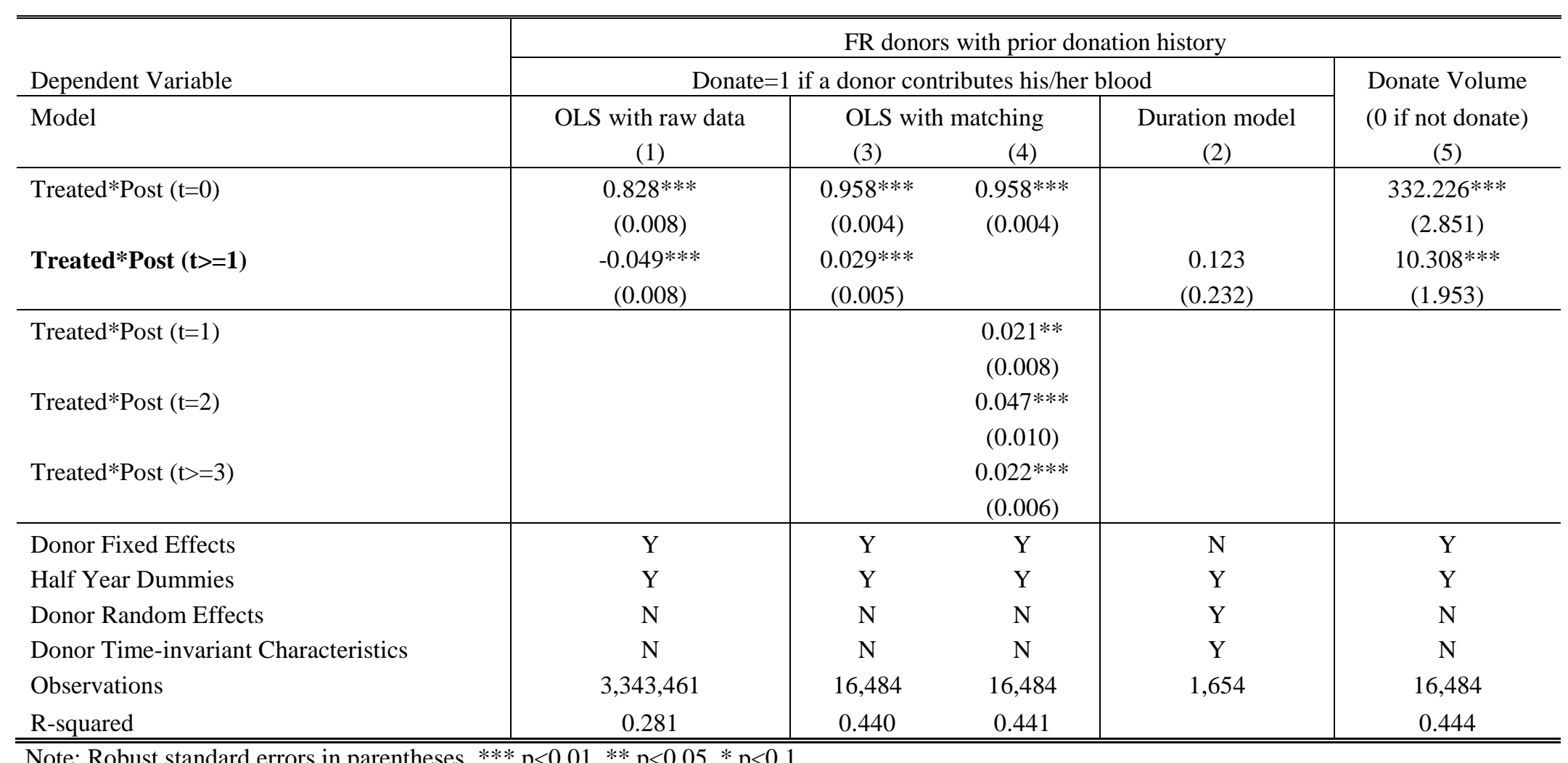


Table 5: Effects of FR donation on FR donors without control for selection

Dependent variable $=1$ if donate voluntarily in a half calendar year All use ordinary least square regression

\begin{tabular}{|c|c|c|c|c|c|c|}
\hline & \multicolumn{3}{|c|}{ FP Donors without prior donation history } & \multicolumn{3}{|c|}{ FP donors with prior donation history } \\
\hline & $\begin{array}{l}\text { OLS wi } \\
\text { Static } \\
(1)\end{array}$ & $\begin{array}{l}\text { natching } \\
\text { Dynamic } \\
\text { (2) }\end{array}$ & $\begin{array}{c}\text { Donate Volume } \\
\text { (0 if not donate) } \\
(3)\end{array}$ & $\begin{array}{l}\text { OLS witl } \\
\text { Static } \\
(4)\end{array}$ & $\begin{array}{l}\text { latching } \\
\text { Dynamic } \\
\quad(5)\end{array}$ & $\begin{array}{c}\text { Donate Volume } \\
\text { (0 if not donate) } \\
(6)\end{array}$ \\
\hline Treated*Post $(\mathrm{t}=0)$ & $\begin{array}{c}0.729 * * * \\
(0.003)\end{array}$ & $\begin{array}{c}0.730 * * * \\
(0.003)\end{array}$ & $\begin{array}{c}245.562 * * * \\
(1.292)\end{array}$ & $\begin{array}{l}0.958 * * * \\
(0.004)\end{array}$ & $\begin{array}{l}0.958 * * * \\
(0.004)\end{array}$ & $\begin{array}{c}332.226^{* * * *} \\
(2.851)\end{array}$ \\
\hline Treated*Post $(\mathrm{t}>=1)$ & $\begin{array}{c}-0.055^{* * *} \\
(0.001) \\
\end{array}$ & & $\begin{array}{c}-17.845^{* * * *} \\
(0.320) \\
\end{array}$ & $\begin{array}{c}0.029 * * * \\
(0.005) \\
\end{array}$ & & $\begin{array}{c}10.308 * * * \\
(1.953) \\
\end{array}$ \\
\hline Treated*Post $(\mathrm{t}=1)$ & & $\begin{array}{c}-0.088 * * * \\
(0.001)\end{array}$ & & & $\begin{array}{c}0.021 * * \\
(0.008)\end{array}$ & \\
\hline Treated*Post $(\mathrm{t}=2)$ & & $\begin{array}{c}-0.045 * * * \\
(0.001)\end{array}$ & & & $\begin{array}{c}0.047 * * * \\
(0.010)\end{array}$ & \\
\hline Treated $*$ Post $(t>=3)$ & & $\begin{array}{c}-0.033 * * * \\
(0.001) \\
\end{array}$ & & & $\begin{array}{c}0.022 * * * \\
(0.006)\end{array}$ & \\
\hline Donor Fixed Effects & $\mathrm{Y}$ & $\mathrm{Y}$ & $\mathrm{Y}$ & $\mathrm{Y}$ & $\mathrm{Y}$ & $\mathrm{Y}$ \\
\hline Half Year Dummies & $\mathrm{Y}$ & $\mathrm{Y}$ & $\mathrm{Y}$ & $\mathrm{Y}$ & $\mathrm{Y}$ & $\mathrm{Y}$ \\
\hline Observations & 309,078 & 309,078 & 309,078 & 16,484 & 16,484 & 16,484 \\
\hline R-squared & 0.847 & 0.85 & 0.817 & 0.440 & 0.441 & 0.444 \\
\hline
\end{tabular}

Note: Robust standard errors in parentheses, $* * * \mathrm{p}<0.01, * * \mathrm{p}<0.05, * \mathrm{p}<0.1$. 
Table 6: Effect of FR, accounting for selection

\begin{tabular}{|c|c|c|c|c|}
\hline \multirow[b]{2}{*}{ Dependent Variable } & \multicolumn{2}{|c|}{ FR Donors without prior donation history } & \multicolumn{2}{|c|}{ FR donors with prior donation history } \\
\hline & $\begin{array}{c}\text { Donate or Not } \\
(1) \\
\end{array}$ & $\begin{array}{c}\text { Donate Volume } \\
\text { (0 if not donate) } \\
(2)\end{array}$ & $\begin{array}{c}\text { Donate or Not } \\
\text { (3) } \\
\end{array}$ & $\begin{array}{c}\text { Donate Volume } \\
\text { (0 if not donate) } \\
(4)\end{array}$ \\
\hline $\mathrm{P}_{\mathrm{N}}$ & $\begin{array}{c}0.081 * * * \\
(0.002)\end{array}$ & $\begin{array}{c}26.719 * * * \\
(0.818)\end{array}$ & $\begin{array}{c}0.033 * * \\
(0.014)\end{array}$ & $\begin{array}{c}11.476 * * * \\
(5.666)\end{array}$ \\
\hline$\Delta \mathrm{P}$ & $\begin{array}{l}-0.00002 \\
(0.00002)\end{array}$ & $\begin{array}{l}-0.006 \\
(0.006)\end{array}$ & $\begin{array}{c}0.063 * * * \\
(0.005)\end{array}$ & $\begin{array}{c}22.693 * * * \\
(2.145)\end{array}$ \\
\hline$\omega$ & $\begin{array}{c}-0.036 * * * \\
(0.001)\end{array}$ & $\begin{array}{c}-11.529 * * * \\
(0.307)\end{array}$ & $\begin{array}{c}0.029 * * * \\
(0.005)\end{array}$ & $\begin{array}{c}10.149 * * * \\
(1.889)\end{array}$ \\
\hline$\Delta \mathrm{P}^{*} \Delta \theta$ & $\begin{array}{c}0.00007 * * * \\
(0.000005)\end{array}$ & $\begin{array}{c}0.021 * * * \\
(0.002)\end{array}$ & $\begin{array}{l}0.111 * \\
(0.060)\end{array}$ & $\begin{array}{l}46.405^{*} \\
(24.510)\end{array}$ \\
\hline$\Delta \theta$ & & & $\begin{array}{l}1.769 * \\
(0.944) \\
\end{array}$ & $\begin{array}{l}2.045^{*} \\
(1.049) \\
\end{array}$ \\
\hline Group Fixed Effects & $\mathrm{Y}$ & $\mathrm{Y}$ & $\mathrm{Y}$ & $\mathrm{Y}$ \\
\hline Half Year Dummies & $\mathrm{Y}$ & $\mathrm{Y}$ & $\mathrm{Y}$ & $\mathrm{Y}$ \\
\hline Observations & 158,635 & 158,637 & 6,826 & 6,826 \\
\hline R-squared & 0.369 & 0.295 & 0.218 & 0.221 \\
\hline
\end{tabular}

Note: Robust standard errors in parentheses, $* * * p<0.01, * * \mathrm{p}<0.05, * \mathrm{p}<0.1$. 
Table 7: Effect of shortage message and FR donation on blood quality

\begin{tabular}{|c|c|c|c|c|c|c|}
\hline \multirow[t]{3}{*}{ Dependent Variable } & \multicolumn{6}{|c|}{ Blood Quality (pass or not) } \\
\hline & \multicolumn{2}{|c|}{ Donors who received messages } & \multicolumn{2}{|c|}{$\begin{array}{c}\text { FR Donors } \\
\text { without prior donation history }\end{array}$} & \multicolumn{2}{|c|}{$\begin{array}{c}\text { FR donors } \\
\text { with prior donation history }\end{array}$} \\
\hline & $(1)$ & $(2)$ & $(3)$ & (4) & $(5)$ & $(6)$ \\
\hline Treated $*$ Post $(t=0)$ & $\begin{array}{l}-0.007 \\
(0.023)\end{array}$ & & $\begin{array}{c}0.002 \\
(0.002)\end{array}$ & & $\begin{array}{l}-0.005 \\
(0.013)\end{array}$ & \\
\hline Treated $*$ Post $(t>=1)$ & & $\begin{array}{l}-0.003 \\
(0.009)\end{array}$ & & $\begin{array}{c}0.011 \\
(0.009)\end{array}$ & & $\begin{array}{c}0.008 \\
(0.005)\end{array}$ \\
\hline Donor Fixed Effects & $\mathrm{Y}$ & $\mathrm{Y}$ & Y & $\mathrm{Y}$ & Y & Y \\
\hline Half Year Dummies & $\mathrm{Y}$ & $\mathrm{Y}$ & $\mathrm{Y}$ & $\mathrm{Y}$ & $\mathrm{Y}$ & $\mathrm{Y}$ \\
\hline Observations & 4,456 & 9,789 & 34,340 & 55,356 & 958 & 924 \\
\hline R-squared & 0.649 & 0.371 & 0.508 & 0.504 & 0.495 & 0.639 \\
\hline
\end{tabular}


Table 8: Back of Envelope Calculation with $\theta_{N}=56.76 \%$

Unit of time $=$ half year

Population $=4,000,000$

$\%$ ever donated before treatment time $=4.5 \%, 10 \%$ or $15 \%$

$\%$ shortage $=\%$ of population that needs blood at a specific $\mathrm{t}-\%$ donate $=1 \%$

$\lambda$ (existing donors) $=\%$ of type- $\mathrm{V}$ existing donors (i.e. those that will donate voluntarily at a specific $\mathrm{t}$ ) $=4 \%$

$\theta_{V}$ (existing donors) $=\%$ of type- $\mathrm{V}$ existing donors that will donate upon FR request $=1$

$\theta_{N}$ (existing donors) $=\%$ of type- $\mathrm{N}$ existing donors that will donate upon FR request $=56.76 \%$

$\lambda$ (no-history) $=\%$ of type- $\mathrm{V}$ no-history donors (i.e. those that will donate voluntarily at a specific $\mathrm{t}$ ) $=0$

$\theta_{N}$ (no history) $=\%$ of no-history donors that will donate upon FR request $=56.76 \%$

\begin{tabular}{|c|c|c|c|c|c|c|}
\hline & & \multirow{2}{*}{$\begin{array}{c}\text { Shortage message } \\
\text { to all existing } \\
\text { donors }\end{array}$} & \multicolumn{3}{|c|}{$\begin{array}{l}\text { FR request to half patients facing shortage } \\
\text { (assume } \theta_{N}=56.76 \% \text { for all FR donors) }\end{array}$} & \multirow{2}{*}{$\begin{array}{c}\text { Difference } \\
\text { (message - FR) }\end{array}$} \\
\hline & & & No-history FR & Existing FR & Total FR & \\
\hline \multirow{4}{*}{$\begin{array}{c}\text { Scenario } 1: \% \text { of } \\
\text { ever donated }= \\
4.5 \%\end{array}$} & $\begin{array}{l}\text { Counts of individuals affected } \\
\text { Extra donations }\end{array}$ & 180000 & 19,100 & 900 & 20,000 & 160,000 \\
\hline & $\mathrm{T}=0$ & 3240 & 10841.2 & 490.4 & $11,331.6$ & $-8,091.6$ \\
\hline & $\mathrm{T}>0$ & 0 & -390.3 & 15.3 & -375.0 & \\
\hline & From $\mathrm{t}=0$ to $\mathrm{t}=9$ & 3240 & 7328.6 & 627.8 & $7,956.4$ & $-4,716.4$ \\
\hline \multirow{4}{*}{$\begin{array}{c}\text { Scenario 2: } \% \text { of } \\
\text { ever donated }= \\
10 \%\end{array}$} & $\begin{array}{l}\text { Counts of individuals affected } \\
\text { Extra donations }\end{array}$ & 400000 & 18,000 & 2,000 & 20,000 & 380,000 \\
\hline & $\mathrm{T}=0$ & 7200 & 10216.8 & 1089.8 & $11,306.6$ & $-4,106.6$ \\
\hline & $\mathrm{T}>0$ & 0 & -367.8 & 33.9 & -333.9 & \\
\hline & From $\mathrm{t}=0$ to $\mathrm{t}=9$ & 7200 & 6906.6 & 1395.1 & $8,301.7$ & $-1,101.7$ \\
\hline \multirow{4}{*}{$\begin{array}{c}\text { Scenario } 3: \% \text { of } \\
\text { ever donated }= \\
15 \%\end{array}$} & $\begin{array}{l}\text { Counts of individuals affected } \\
\text { Extra donations }\end{array}$ & 600000 & 17,000 & 3,000 & 20,000 & 580,000 \\
\hline & $\mathrm{T}=0$ & 10800 & 9649.2 & 1634.7 & 11283.9 & -483.9 \\
\hline & $\mathrm{T}>0$ & 0 & -347.4 & 50.9 & -296.5 & \\
\hline & From $t=0$ to $t=9$ & 10800 & 6522.9 & 2092.7 & 8615.5 & 2184.5 \\
\hline
\end{tabular}


Table 9: Back of Envelope with different $\theta_{N}$ for no-history FR donors

Unit of time $=$ half year

Population $=4,000,000$

$\%$ ever donated before treatment time $=4.5 \%, 10 \%$ or $15 \%$

$\%$ shortage $=\%$ of population that needs blood at a specific $\mathrm{t}-\%$ donate $=1 \%$

$\lambda$ (existing donors) $=\%$ of type- $\mathrm{V}$ existing donors (i.e. those that will donate voluntarily at a specific $\mathrm{t}$ ) $=4 \%$

$\theta_{V}$ (existing donors) $=\%$ of type- $\mathrm{V}$ existing donors that will donate upon FR request $=1$

$\theta_{N}$ (existing donors) $=\%$ of type- $\mathrm{N}$ existing donors that will donate upon FR request $=56.76 \%$

$\lambda$ (no-history) $=\%$ of type- $\mathrm{V}$ no-history donors (i.e. those that will donate voluntarily at a specific $\mathrm{t}$ ) $=0$

$\theta_{N}$ (no history) $=\%$ of no-history donors that will donate upon FR request $=56.76 \%, 100 \%$, or $30 \%$

\begin{tabular}{|c|c|c|c|c|c|c|c|}
\hline & \multirow[b]{2}{*}{$\begin{array}{l}\text { Shortage } \\
\text { message to } \\
\text { all existing } \\
\text { donors }\end{array}$} & \multicolumn{6}{|c|}{ FR request to half patients facing shortage } \\
\hline & & $\begin{array}{r}\theta_{N}(\text { no h } \\
\text { Total FR } \\
\end{array}$ & $\begin{array}{l}\text { tory) }=56.76 \% \\
\text { Difference } \\
\text { (message - FR) }\end{array}$ & $\begin{array}{r}\theta_{N}(\text { no } \\
\text { Total FR }\end{array}$ & $\begin{array}{l}\text { story) }=100 \% \\
\text { Difference } \\
\text { (message - FR) }\end{array}$ & $\begin{array}{r}\theta_{N}(\text { no } \\
\text { Total FR }\end{array}$ & $\begin{array}{l}\text { istory) }=30 \% \\
\text { Difference } \\
\text { (message - FR) }\end{array}$ \\
\hline $\begin{array}{l}\text { Scenario 1: } \% \text { donated }=4.5 \% \\
\text { Counts of individuals affected } \\
\text { Extra donations }\end{array}$ & 180000 & 20,000 & 160,000 & 20000 & 160000 & 20000 & 160000 \\
\hline $\begin{array}{l}\mathrm{T}=0 \\
\mathrm{~T}>0\end{array}$ & $\begin{array}{c}3240 \\
0\end{array}$ & $\begin{array}{l}11331.6 \\
-375.0\end{array}$ & -8091.6 & $\begin{array}{c}19590.4 \\
-672.3\end{array}$ & -16350.4 & $\begin{array}{l}6220.4 \\
-191.0\end{array}$ & -2980.4 \\
\hline From $\mathrm{t}=0$ to $\mathrm{t}=9$ & 3240 & 7956.4 & -4716.4 & 13539.4 & -10299.4 & 4501.3 & -1261.3 \\
\hline $\begin{array}{l}\text { Scenario } 2: \% \text { donated }=10 \% \\
\text { Counts of individuals affected } \\
\text { Extra donations }\end{array}$ & 400000 & 20,000 & 380,000 & 20000 & 380000 & 20000 & 380000 \\
\hline $\begin{array}{l}\mathrm{T}=0 \\
\mathrm{~T}>0\end{array}$ & $\begin{array}{c}7200 \\
0\end{array}$ & $\begin{array}{l}11306.6 \\
-333.9\end{array}$ & -4106.6 & $\begin{array}{c}19089.8 \\
-614.1\end{array}$ & -11889.8 & $\begin{array}{l}6489.8 \\
-160.5\end{array}$ & 710.2 \\
\hline From $\mathrm{t}=0$ to $\mathrm{t}=9$ & 7200 & 8301.7 & -1101.7 & 13563.1 & -6363.1 & 5045.5 & 2154.5 \\
\hline $\begin{array}{l}\text { Scenario } 3: \% \text { donated }=15 \% \\
\text { Counts of individuals affected } \\
\text { Extra donations }\end{array}$ & 600000 & 20,000 & 580,000 & 20000 & 580000 & 20000 & 580000 \\
\hline $\begin{array}{l}\mathrm{T}=0 \\
\mathrm{~T}>0\end{array}$ & $\begin{array}{c}10800 \\
0\end{array}$ & $\begin{array}{l}11283.9 \\
-296.5\end{array}$ & -483.9 & $\begin{array}{c}18634.7 \\
-561.1\end{array}$ & -7834.7 & $\begin{array}{l}6734.7 \\
-132.7\end{array}$ & 4065.3 \\
\hline From $\mathrm{t}=0$ to $\mathrm{t}=9$ & 10800 & 8615.5 & 2184.5 & 13584.7 & -2784.7 & 5540.3 & 5259.7 \\
\hline
\end{tabular}

